\title{
Protective role of antioxidants on thioacetamide-induced acute hepatic encephalopathy: Biochemical and Ultrastructural study
}

\author{
Mustafa H.N. a,*, Sally A. El Awdan ${ }^{\mathrm{b}}$, Gehan A. Hegazy ${ }^{\mathrm{c}, \mathrm{d}}$ \\ a Anatomy Department, Faculty of Medicine, King Abdulaziz University, Jeddah, Saudi Arabia \\ b Pharmacology Department, National Research Center, Cairo, Egypt \\ c Clinical Biochemistry Department, Faculty of Medicine, King Abdulaziz University, Jeddah, Saudi Arabia \\ ${ }^{\mathrm{d}}$ Medical Biochemistry Department, National Research Center, Cairo, Egypt
}

\section{A R T I C L E I N F O}

\section{Article history:}

Received 5 November 2012

Received in revised form 25 April 2013

Accepted 3 June 2013

Available online 19 July 2013

\section{Keywords:}

Antioxidant

Hepatic encephalopathy

Thioacetamide

Vitamin C

Vitamin E

Ultrastructure

\begin{abstract}
A B S T R A C T
Thioacetamide (TAA) has been used in development of animal models of acute hepatic encephalopathy (AHE). This experimental study was designed to evaluate effects of oral administration of vitamin C, vitamin $\mathrm{E}$ and their combination on liver and brain enzymes and their histologic and ultrastructure changes. Eighty Wistar rats were included and divided into five groups (16 each). Group 1 (control) received saline once intraperitoneally (IP) then administered orally saline and corn oil for 3 days. Group 2 [hepatotoxic (TAA)] were received TAA ( $300 \mathrm{mg} / \mathrm{kg}$ ) once intraperitoneally (IP). Group 3 (vitamin C and TAA) received TAA (300 mg/kg) once intraperitoneally (IP) and then administered orally vitamin C ( $100 \mathrm{mg} / \mathrm{kg})$ daily for 3 days. Group 4 (vitamin E and TAA) received TAA $(300 \mathrm{mg} / \mathrm{kg}$ ) once intraperitoneally (IP) and then administered orally vitamin $\mathrm{E}(200 \mathrm{mg} / \mathrm{kg})$ daily for 3 days. Group 5 (vitamin C and vitamin E and TAA) received TAA $(300 \mathrm{mg} / \mathrm{kg}$ ) once intraperitoneally (IP) and then administered orally vitamin C $(100 \mathrm{mg} / \mathrm{kg})$ in combination with vitamin $\mathrm{E}(200 \mathrm{mg} / \mathrm{kg})$ daily for 3 days. All rats were sacrificed $24 \mathrm{~h}$ after last treatment under anesthesia. Blood samples were collected and serum was obtained for analysis of aspartate aminotransferase (AST), alanine aminotransferase (ALT), gamma-glutamyl transferase (GGT), total protein, triglyceride, cholesterol using spectrophotometer and ELISA kits. Liver and brain were extracted and tissue homogenate was used to measure malondialdehyde (MDA), reduced glutathione (GSH) and nitric oxide (NO). Histological and ultrastructure examination were done. TAA induced significant increase of MDA and decreased in GSH and NO in both liver and brain homogenate with more liver affection, and increased in serum levels of AST, ALT, triglyceride, cholesterol and decreased in total protein. Furthermore, there is decrease in serum levels of AST, ALT, triglyceride, cholesterol and tissue levels of MDA and elevated serum total protein and tissue GSH and NO under the umbrella of vitamin C and vitamin E and their combination, although vitamin $\mathrm{E}$ is more efficient. These data showed protective effect of vitamins $\mathrm{C}$ and $\mathrm{E}$, especially vitamin $\mathrm{E}$ against oxidative stress and hepatic and brain damage, and histological architecture of the liver in rats' model of acute hepatic encephalopathy elicited by TAA.
\end{abstract}

Crown Copyright $\odot 2013$ Published by Elsevier Ltd. All rights reserved.

\section{Introduction}

Hepatic encephalopathy (HE) is a neuropsychiatric syndrome resulting from acute or chronic liver failure (Lizardi-Cervera et al., 2003). Hepatic encephalopathy affects a considerable number of patients worldwide with a mortality index ranging from 50 to 90\% (Raghavan and Marik, 2006). This condition can cause a wide range of clinical manifestations, which include psychomotor dysfunctions, sensory abnormalities, poor concentration, impaired

\footnotetext{
* Corresponding author at: King Abdulaziz University, Faculty of Medicine, Anatomy Department, P.O. Box 80205, Jeddah 21589, Saudi Arabia. Tel.: +966566764762.

E-mail address: hesham977@hotmail.com (H.N. Mustafa).
}

memory and increased reaction time. In its most severe form, patients may develop stupor, coma and death (Bass, 2007). In spite of that, the mechanism of hepatic encephalopathy not fully explained; many researchers suggested that ammonia play the main role in hepatic encephalopathy pathogenesis.

Thioacetamide is a hepatotoxin frequently used in experimental studies due to its efficacy in inducing hepatic failure in rodents. Following hepatic failure, TAA is able to induce hepatic encephalopathy in rats (Avraham et al., 2006). Researchers have stated that centrilobular necrosis is established with single dose of this hepatotoxic agent, while with chronic administration cirrhosis is created, liver cell adenomas and liver cancer (Waters et al., 2005).

Acute and chronic liver diseases due to different causes such as exposures to liver toxins, liver ischemia/reperfusion injury, and viral hepatitis are established because of oxidative stress 
(McDonough, 2003). Hence, many studies have been done to test different antioxidants or free radicals scavengers for the avoidance and management of acute and chronic liver damages. The results of some of those studies revealed that antioxidants playing role in prevention and treatment of chronic liver disease (Bruck et al., 2001). Consequently, elimination of free radicals in both the lipid and the aqueous phases, in extracellular and intracellular spaces is the main strategy for prevention of oxidative stress (Singh et al., 2004).

Vitamin C (ascorbic acid and ascorbate) is considered the firstorder antioxidant, because of its antioxidant, membrane stabilizing properties and the water-soluble property (Al-Attar, 2011).Vitamin $\mathrm{E}$ is a main non-enzymatic antioxidant, present in the lipid phase. There are eight forms of vitamin $\mathrm{E}$ but the form that possesses the highest biological activity is $\alpha$-tocopherol (Blatt et al., 2001).

The aim of the present experimental study was to assess the beneficial effects of vitamins C, E and their combination in thioacetamide induced acute hepatic encephalopathy in rat model. Hepatic damage was assessed by measurement of serum levels of alanine aminotransferase (ALT), aspartate aminotransferase (AST) activities, total protein, cholesterol and triglycerides. Oxidative stress was assessed by measuring liver and brain tissue levels of malondialdehyde (MDA) as an oxidant and reduced glutathione (GSH) and nitric oxide (NO) levels as antioxidant. The morphological picture of TAA and antioxidants effects on hepatic tissues were examined using light and transmission electron microscopy.

\section{Materials and methods}

\subsection{Animals}

Male Wistar rats weighing between 150 and $170 \mathrm{~g}$ at the beginning of the study were purchased from the animal house of the King Fahd Medical Research Center, King Abdulaziz University. They were subjected to controlled conditions of temperature $\left(25 \pm 3^{\circ} \mathrm{C}\right)$, 50-60\% humidity, illumination (12-h light:12-h dark cycle, lights on at 08:00 h) and were provided with standard pellet diet and water ad libitum for at least one week before starting the experiment. All animal cares and procedures were in accordance with the European Communities Council Directive of 24 November 1986 (86/609/ECC) and the R.D. 223/1988, and were approved by Ethical Committee of Faculty of Medicine, King Abdulaziz University, Jeddah, Saudi Arabia. All experimental procedures were performed from 8 to 10 a.m.

\subsection{Preparation of drugs}

All the reagents were purchased from Sigma (St. Louis, MO, USA). TAA was prepared freshly by dissolving in sterile distilled water and stirred well until all crystals were dissolved. Vitamin $C$ was dissolved in sterile distilled water. Vitamin E was dissolved in corn oil.

\subsection{Experimental protocols}

Eighty rats were used to perform the study were divided into five groups with 16 animals each as follows.

Group 1 (control group): rats received saline $(2 \mathrm{~mL} / \mathrm{kg})$ intraperitoneally (IP) once then administered orally saline and corn oil at dose of $5 \mathrm{~mL} / \mathrm{kg}$ daily for 3 days.

Group 2 [hepatotoxic (TAA) group]: rats received TAA $(300 \mathrm{mg} / \mathrm{kg}$ ) intraperitoneally (IP) once (Pawa and Ali, 2004).

Group 3 (vitamin C and TAA): rats received TAA $(300 \mathrm{mg} / \mathrm{kg}$ ) intraperitoneally (IP) once on the first day and then administered orally vitamin C ( $100 \mathrm{mg} / \mathrm{kg})$ daily for 3 days after $24 \mathrm{~h}$ of TAA injection (Ming et al., 2006).

Group 4 (vitamin E and TAA): rats were received TAA (300 mg/kg) once intraperitoneally (IP) on the first day and then administered orally vitamin $\mathrm{E}(200 \mathrm{mg} / \mathrm{kg})$ daily for 3 days after $24 \mathrm{~h}$ of TAA injection (Ming et al., 2006).

Group 5 (vitamin C, vitamin E and TAA): rats received TAA $(300 \mathrm{mg} / \mathrm{kg}$ ) once intraperitoneally (IP) on the first day and then administered orally vitamin $C(100 \mathrm{mg} / \mathrm{kg})$ and vitamin $\mathrm{E}$ (200 mg/kg) daily for 3 days.

The animals received dextrose water and ringer lactate solutions $(10 \mathrm{mg} / \mathrm{kg} /$ day, i.p.) to prevent renal failure, hypoglycemia and electrolyte imbalance till the end of the experiment. All rats were sacrificed under anesthesia $24 \mathrm{~h}$ after the last treatment and overnight fasting. Before sacrifice, blood samples were collected from the retro-orbital venous plexus. The liver and brain were extracted and frozen immediately at $-80^{\circ} \mathrm{C}$.

\subsection{Preparing serum and tissue homogenates}

Blood samples (approximately $4 \mathrm{~mL}$ ) were taken from each rat from retro-orbital veins, using a sterile syringe, during sacrifice at end of experiments. These samples were kept at room temperature for $30 \mathrm{~min}$ and centrifuged at $3000 \mathrm{rpm}$ for $10 \mathrm{~min}$. Serum samples were stored in a freezer $\left(-20^{\circ} \mathrm{C}\right)$ for use in biochemical analyses [aspartate transaminase (AST), alanine transaminase (ALT), gamma glutamyl transferase (GGT), total protein, triglyceride and total cholesterol].

After sacrifice, the abdomen was open wide and the liver and brain were removed and washed three times with cold physiological saline $(0.9 \% \mathrm{NaCl})$. The liver and brain were weighted and homogenized. Tissue samples were placed into labeled plastic cups and wrapped in aluminum foil, then stored in $-80^{\circ} \mathrm{C}$ until analysis. Tissue homogenates were used for oxidative stress markers analysis.

\subsection{Hepatic biochemical parameters in serum}

Serum AST and ALT were determined according to the method of Reitman and Frankel (1957) using ELISA kits supplied by Biodiagnostic Company (Cairo, Egypt). GGT activity was determined according to method of Goldbarg et al. (1960) for measurement of catalytic concentration of enzymes using ELISA kit supplied by Gamma Trade (Cairo, Egypt). Total protein was determined spectrophotometrically as described by Bradford (1976) using bovine serum as a standard. Total cholesterol and triglyceride were determined by colorimetric methods using kits supplied by Biodiagnostic Company (Cairo, Egypt).

\subsection{Oxidative stress markers activities in tissue homogenates}

Tissue homogenate malondialdehyde (MDA) level was measured using the thiobarbituric acid reactive substances (TBARS) assay, as described by Mihara and Uchiyama (1978) and expressed as nmol/g wet tissues. Lipid peroxidation products were estimated by the determination of the level of TBARS that were measured as malondialdehyde (MDA). The latter is the decomposition product of the process of lipid peroxidation and is used as an indicator of this process. The principle of assay depends on the colorimetric determination of a pink pigment product, resulting from the reaction of TBARS with thiobarbituric acid (TBA) in an acidic medium at high temperature. Reduced glutathione (GSH) content was determined in stomach homogenate according to the method of Beutler et al. (1963) and expressed as $\mathrm{mg} / \mathrm{g}$ wet tissue. The method depends on the fact that both protein and non-protein thiol ( $\mathrm{SH}-$ ) groups (mainly GSH) react with Ellman's reagent [5,5'-dithiobis 
(2-nitrobenzoic acid)] (Ellman, 1959) to form a stable yellow color of 5-mercapto-2-nitrobenzoic acid, which can be measured colorimetrically at $412 \mathrm{~nm}$. Tissue NO metabolites were determined according to the method described by Miranda et al. (2001) and expressed as $\mu \mathrm{M} / \mathrm{g}$ wet tissue. The assay determines total NOx content based on the reduction of any nitrate to nitrite by vanadium followed by the detection of total nitrite (intrinsic + nitrite obtained from reduction of nitrate) by Griess reagent. The Griess reaction leads to the formation of a chromophore from the diazotization of sulfanilamide by acidic nitrite followed by coupling with bicyclic amines such as $\mathrm{N}$-(1-naphthyl) ethylenediamine. The chromophoric azo derivative can be measured colorimetrically at $540 \mathrm{~nm}$.

\subsection{Histological study}

For light microscopic examination, the Liver specimens excised and fixed in $10 \%$ neutral buffered formalin for $24 \mathrm{~h}$ dehydrated in ascending ethanol series, cleared in xylene and embedded in paraffin wax. Then cut into $(3-5 \mu \mathrm{m})$ thickness and stained with hematoxylin and eosin, then observed and photographed for details using Olympus BX53 microscope equipped with an Olympus DP21 camera.

\subsection{Histochemical study}

Bromophenol blue technique was used for the demonstrating of total proteins (Mazia et al., 1953).

\subsection{Ultrastructure study}

Liver specimens were fixed overnight at $4{ }^{\circ} \mathrm{C}$ in $2.5 \%$ glutaraldehyde in $0.1 \mathrm{M}$ phosphate buffer solution ( $\mathrm{pH} 7.4$ ). Specimens were then cut into small pieces of $1 \mathrm{~mm}^{3}$, post-fixed in $2 \%$ osmium tetroxide in phosphate buffer for $2 \mathrm{~h}$ at room temperature. Following fixation, tissues were dehydrated at increasing concentrations of ethanol. They were then embedded in Epon-Araldite. Ultrathin sections $(60-70 \mathrm{~nm}$ ) prepared with Ultratome III (LKB Instruments Inc., Gaithersburg, MD) equipped with a diamond knife. The sections were stained with uranyl acetate saturated in $70 \%$ ethanol, and lead citrate (Reynolds, 1963). Tissue sections were evaluated using a JEOL transmission electron microscope (JEM-1200EX II, JEOL, Tokyo, Japan).

\subsection{Statistical analysis}

Data will be analyzed using SPSS (version 20; SPSS, Chicago, IL, USA). Results are expressed as mean \pm SD and minimum-maximum. Comparisons of quantitative variables among groups were made using one-way analysis of variance (ANOVA) or the corresponding non-parametric (Kruskal-Wallis) test, as required. Post hoc comparisons were performed using the LSD test. Statistical correlations between measured variables were calculated using the Pearson correlation analysis method. $P$-value $<0.05$ was considered significant.

\section{Results}

Table 1 showed that in TAA group, serum levels of AST, ALT, triglyceride and cholesterol were significantly higher than healthy controls $(P<0.0001, P<0.0001, P<0.0001, P<0.007)$. In vitamin $C$ and TAA, serum levels of AST, ALT, total protein and cholesterol were significantly higher than healthy controls $(P<0.012, P<0.021$, $P<0.012, P<0.043$ ); meanwhile levels of AST, ALT and triglyceride were significantly lower $(P<0.042, P<0.007, P<0.0001)$ while total protein was significantly higher $(P<0.001)$ than TAA group. In vitamin E and TAA, serum levels of AST and ALT were significantly higher $(P<0.035, P<0.007)$ while triglyceride was significantly lower $(P<0.0001)$ than healthy controls; meanwhile serum levels of AST, ALT, triglyceride and cholesterol were significantly lower $(P<0.0001, P<0.022, P<0.0001, P<0.002)$ than TAA group; while total protein, triglyceride and cholesterol were lower $(P<0.012$, $P<0.012, P<0.016)$ than vitamin $C$ and TAA group. In vitamin $C$ and vitamin $E$ and TAA group, serum levels of AST, ALT and cholesterol were significantly higher $(P<0.0001, P<0.023, P<0.005)$ than healthy controls; meanwhile levels of ALT and triglyceride was significantly lower $(P<0.007, P<0.001)$ than TAA group; while AST and triglyceride were higher $(P<0.042, P<0.011)$ while total protein was lower $(P<0.008)$ than vitamin $C$ and TAA group; AST, triglyceride and cholesterol were higher than vitamin $E$ and TAA group $(P<0.0001, P<0.0001, P<0.002)$.

Table 2 illustrated that in TAA group, Liver-MDA and brainMDA were higher $(P<0.007, P<0.005)$, while liver-GSH, liver-NO, brain-NO were lower $(P<0.004, P<0.0001, P<0.013)$ than healthy controls. In vitamin $C$ and TAA group, brain-MDA and brainNO were lower $(P<0.002, P<0.019)$ than healthy controls, while liver-MDA, brain-MDA were lower $(P<0.0001, P<0.0001)$, while liver-NO was higher $(P<0.003)$ than TAA. In vitamin $E$ and TAA group, brain-MDA, liver-NO and brain-NO were lower $(P<0.0001$, $P<0.003, P<0.019)$ while brain-GSH was higher $(P<0.017)$ than healthy controls; brain-MDA was lower $(P<0.0001)$ while liverGSH, brain-GSH were higher $(P<0.0001, P<0.0001)$ than TAA group; brain-GSH was higher $(P<0.009)$ while liver-NO was lower $(P<0.025)$ than vitamin $C$ and TAA.

In vitamin $C$ and vitamin $E$ and TAA group, brain-MDA, liverNO, brain-NO were lower $(P<0.002, P<0.003, P<0.031)$ while liverGSH was higher $(P<0.017)$ than healthy controls; liver-MDA and brain-MDA were lower $(P<0.001, P<0.0001)$ while liver-GSH and brain-GSH were higher $(P<0.0001, P<0.040)$ than TAA; liver-GSH was higher $(P<0.0001)$ while liver-NO was lower $(P<0.026)$ than vitamin $C$ and TAA group; liver-GSH was higher $(P<0.0001)$ than vitamin $\mathrm{E}$ and TAA group.

In control group, positive significant correlations were found between ALT with triglycerides $(r=0.874, P<0.023)$ and liverMDA $(r=0.927, P<0.008)$; between total protein with cholesterol $(r=0.917, P<0.028)$, between brain-GSH with brain-NO $(r=0.895$, $P<0.016)$ (Figs. 8 and 9).

In TAA group, a positive correlation was found between ALT with liver-GSH $(r=0.850, P<0.032)$, while negative correlations were found between total protein with brain-GSH $(r=-0.881$, $P<0.048)$; between cholesterol with liver-NO $(r=-0.837, P<0.038)$ (Figs. 10-12).

In vitamin $C$ and TAA group, a positive correlation was found between AST with liver-GSH $(r=0.951, P<0.004)$ (Fig. 13).

In vitamin $\mathrm{E}$ and TAA group, a positive correlation was found between AST with brain-NO $(r=0.996, P<0.0001)$ (Fig. 14).

In vitamin $C$ and vitamin $E$ and TAA group, a negative correlation was found between AST with total protein $(r=-0.891, P<0.042)$ (Fig. 15).

\subsection{Histological results of liver specimens}

Examination of H\&E stained sections of control liver showed the characteristic hepatic architecture (Fig. 1A). Sections of thioacetamide (TAA) rats revealed massive hepatocytic necrosis, comprising bridging necrosis, inflammatory cells influx (Fig. 1B). Liver sections of TAA rats treated with vitamin $C$ revealed that the hepatocytes showing coagulative necrosis and apoptosis with intact hepatocytes in the central zone (Fig. 1C). Liver sections of TAA rats treated with vitamin $\mathrm{E}$ showed marked regeneration and improvement in hepatic cells around the central vein and prominent 
Table 1

Effect of vitamin C and vitamin E and their combination in thioacetamide induced liver injury in serum liver functions in different studied groups.

\begin{tabular}{|c|c|c|c|c|c|c|}
\hline Groups & AST (U/L) & $\operatorname{ALT}(\mathrm{U} / \mathrm{L})$ & GGT (U/L) & Total protein $(\mathrm{g} / \mathrm{dL})$ & Triglycerides (mg/dL) & Cholesterol (mg/dL) \\
\hline Control & $\begin{array}{l}21.24 \pm 11.15 \\
6.90-30.50\end{array}$ & $\begin{array}{l}43.67 \pm 14.53 \\
19.00-55.00\end{array}$ & $\begin{array}{l}3.94 \pm 6.59 \\
0.00-17.30\end{array}$ & $\begin{array}{l}8.07 \pm 1.48 \\
6.34-10.36\end{array}$ & $\begin{array}{l}95.16 \pm 10.89 \\
82.42-109.51\end{array}$ & $\begin{array}{l}71.15 \pm 5.86 \\
64.71-78.99\end{array}$ \\
\hline Thioacetamide & $\begin{array}{l}146.17 \pm 14.80 \\
117.00-159.00 \\
P<\mathbf{0 . 0 0 0 1}\end{array}$ & $\begin{array}{l}133.33 \pm 16.4 \\
115.00-161.00 \\
\boldsymbol{P}<\mathbf{0 . 0 0 0 1}\end{array}$ & $\begin{array}{l}10.46 \pm 6.85 \\
3.47-17.37 \\
P<0.117\end{array}$ & $\begin{array}{l}7.31 \pm 0.95 \\
6.19-8.63 \\
P<0.234\end{array}$ & $\begin{array}{l}151.59 \pm 28.08 \\
102.59-174.64 \\
\boldsymbol{P}<\mathbf{0 . 0 0 0 1}\end{array}$ & $\begin{array}{l}126.33 \pm 50.82 \\
71.43-192.44 \\
\boldsymbol{P}<\mathbf{0 . 0 0 7}\end{array}$ \\
\hline Vitamin $C$ and thioacetamide & $\begin{array}{l}103.83 \pm 33.63 \\
39.00-130.00 \\
\boldsymbol{P}<\mathbf{0 . 0 1 2} \\
{ }^{*} \boldsymbol{P}<\mathbf{0 . 0 4 2}\end{array}$ & $\begin{array}{l}84.83 \pm 32.11 \\
40.00-125.00 \\
\boldsymbol{P}<\mathbf{0 . 0 2 1} \\
{ }^{*} \boldsymbol{P}<\mathbf{0 . 0 0 7}\end{array}$ & $\begin{array}{l}6.48 \pm 6.37 \\
2.32-17.37 \\
P<0.504 \\
{ }^{*} P<0.348\end{array}$ & $\begin{array}{l}9.80 \pm 0.67 \\
9.07-10.69 \\
\boldsymbol{P}<\mathbf{0 . 0 1 2} \\
{ }^{*} \boldsymbol{P}<\mathbf{0 . 0 0 1}\end{array}$ & $\begin{array}{l}79.73 \pm 17.06 \\
57.06-101.44 \\
P<0.165 \\
{ }^{*} \boldsymbol{P}<\mathbf{0 . 0 0 0 1}\end{array}$ & $\begin{array}{l}111.06 \pm 26.69 \\
80.67-146.22 \\
\boldsymbol{P}<\mathbf{0 . 0 4 3} \\
{ }^{*} P<0.423\end{array}$ \\
\hline Vitamin E and thioacetamide & $\begin{array}{l}65.33 \pm 52.11 \\
21.00-163.00 \\
\boldsymbol{P}<\boldsymbol{0 . 0 3 5} \\
{ }^{*} \boldsymbol{P}<\mathbf{0 . 0 0 0 1} \\
{ }^{* *} P<0.063\end{array}$ & $\begin{array}{l}92.50 \pm 34.16 \\
47.00-140.00 \\
\boldsymbol{P}<\boldsymbol{0 . 0 0 7} \\
{ }^{*} \boldsymbol{P}<\mathbf{0 . 0 2 2} \\
{ }^{* *} P<0.649\end{array}$ & $\begin{array}{l}5.10 \pm 2.67 \\
2.32-9.26 \\
P<0.761 \\
{ }^{*} P<0.209 \\
{ }^{* *} P<0.725\end{array}$ & $\begin{array}{l}8.08 \pm 0.53 \\
7.16-8.50 \\
P<0.996 \\
{ }^{*} P<0.232 \\
{ }^{* *} \boldsymbol{P}<\mathbf{0 . 0 1 2}\end{array}$ & $\begin{array}{l}50.49 \pm 6.62 \\
42.07-56.48 \\
\boldsymbol{P}<\mathbf{0 . 0 0 0 1} \\
{ }^{*} \boldsymbol{P}<\mathbf{0 . 0 0 0 1} \\
{ }^{* *} \boldsymbol{P}<\mathbf{0 . 0 1 2}\end{array}$ & $\begin{array}{l}62.89 \pm 18.07 \\
27.73-74.79 \\
P<0.663 \\
{ }^{*} \boldsymbol{P}<\boldsymbol{0 . 0 0 2} \\
{ }^{* *} \boldsymbol{P}<\mathbf{0 . 0 1 6}\end{array}$ \\
\hline \multirow{2}{*}{$\begin{array}{l}\text { Vitamin } C \text { and vitamin } \mathrm{E} \text { and } \\
\text { thioacetamide }\end{array}$} & $151.50 \pm 41.08$ & $83.92 \pm 38.48$ & $9.50 \pm 7.25$ & $7.96 \pm 1.01$ & $109.41 \pm 22.46$ & $129.55 \pm 40.13$ \\
\hline & $\begin{array}{l}90.00-198.00 \\
\boldsymbol{P}<\mathbf{0 . 0 0 0 1} \\
{ }^{*} P<0.790 \\
{ }^{* *} \boldsymbol{P}<\mathbf{0 . 0 4 2} \\
{ }^{* * *} \boldsymbol{P}<\mathbf{0 . 0 0 0 1}\end{array}$ & $\begin{array}{l}40.25-141.00 \\
\boldsymbol{P}<\mathbf{0 . 0 2 3} \\
{ }^{*} \boldsymbol{P}<\mathbf{0 . 0 0 7} \\
{ }^{* *} P<0.957 \\
{ }^{* * *} P<0.611\end{array}$ & $\begin{array}{l}2.32-17.37 \\
P<0.152 \\
{ }^{*} P<0.818 \\
{ }^{* *} P<0.449 \\
{ }^{* * *} P<0.272\end{array}$ & $\begin{array}{l}6.89-9.52 \\
P<0.856 \\
{ }^{*} P<0.309 \\
{ }^{* *} \boldsymbol{P}<\boldsymbol{0 . 0 0 8} \\
{ }^{* * *} P<0.852\end{array}$ & $\begin{array}{l}77.81-134.29 \\
P<0.199 \\
{ }^{*} \boldsymbol{P}<\mathbf{0 . 0 0 1} \\
{ }^{* *} \boldsymbol{P}<\mathbf{0 . 0 1 1} \\
{ }^{* * *} \boldsymbol{P}<\mathbf{0 . 0 0 0 1}\end{array}$ & $\begin{array}{l}84.03-177.31 \\
\boldsymbol{P}<\mathbf{0 . 0 0 5} \\
{ }^{*} P<0.865 \\
{ }^{* *} P<0.333 \\
{ }^{* * *} \boldsymbol{P}<\mathbf{0 . 0 0 2}\end{array}$ \\
\hline
\end{tabular}

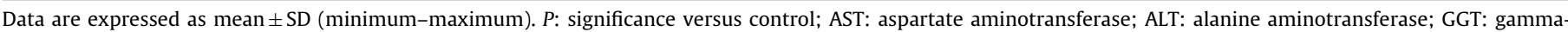
glutamyltransferase.

The bold values represent significant $P<0.05$ while un-bold values represent non-significant $P$ values.

${ }^{*} P$ : significance versus thioacetamide.

** $P$ : significance versus vitamin C $(100 \mathrm{mg} / \mathrm{kg})$ and thioacetamide.

${ }^{* * *} P$ : significance versus vitamin $\mathrm{E}(100 \mathrm{mg} / \mathrm{kg})$ and thioacetamide.

improvement around the portal area (Fig. 1D). Liver sections of TAA rats treated with a combination of vitamin $C$ and vitamin $E$ revealed vacuolation and congestion around the portal vein. While the hepatocytes in the central zone are not affected (Fig. 1E).

\subsection{Histochemical results of liver specimens}

With reference to bromophenol blue reactivity for total protein demonstration, the hepatocytes of control rats showed positive reaction and moderate protein content (Fig. 2A). In TAA rats, the hepatocytes in pericentral and periportal regions showed faint reaction, resulting from a decrease in protein contents (Fig. 2B). Treatment TAA rats with vitamin $C$, resulted in moderate improvement in protein content in liver cells (Fig. 2C). Treatment TAA rats with vitamin $\mathrm{E}$, resulted in marked improvement in protein content in liver cells (Fig. 2D). After treatment TAA rats with combined vitamin $C$ and vitamin $\mathrm{E}$, there is moderate improvement in protein content in liver cells (Fig. 2E).

Table 2

Effect of vitamin $\mathrm{C}$ and vitamin $\mathrm{E}$ and their combination in thioacetamide induced liver injury in liver and brain oxidative stress markers in different studied groups.

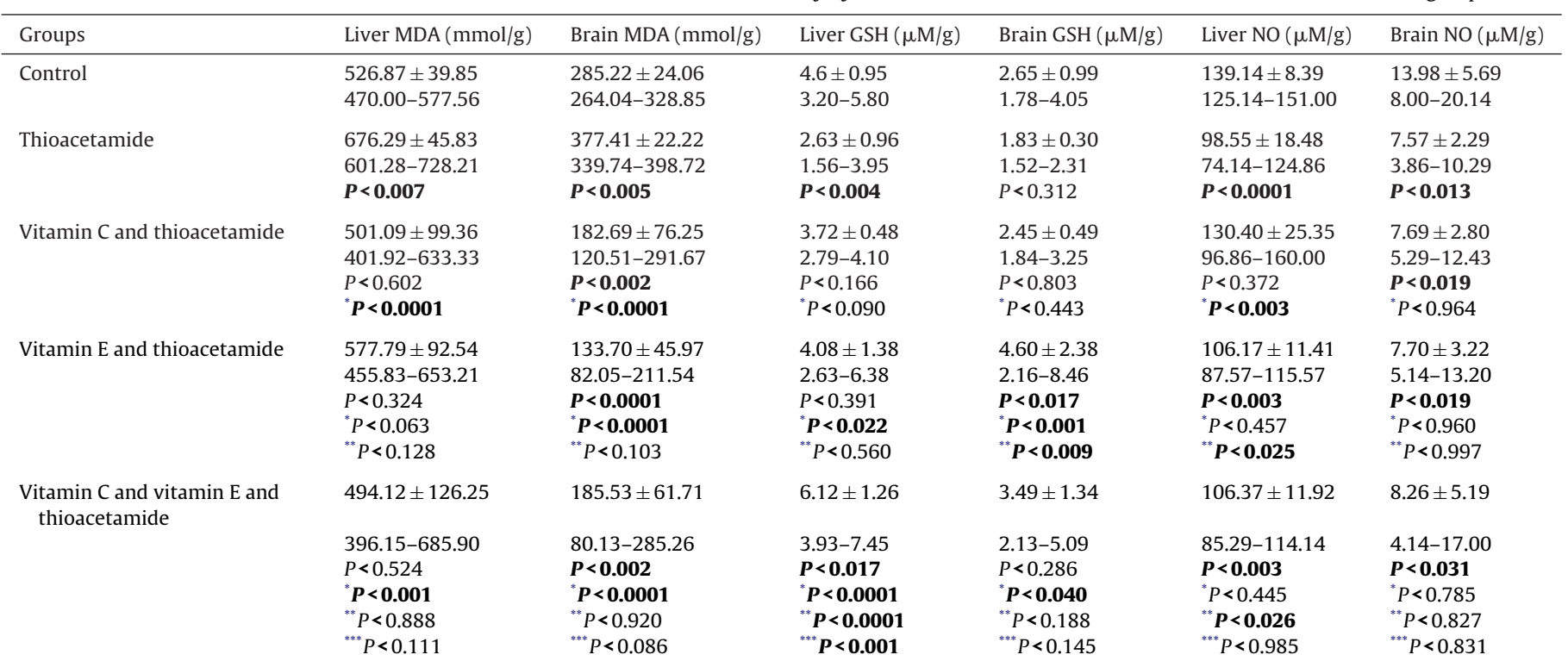

Data are expressed as mean \pm SD (minimum-maximum). P: significance versus control. MDA: malondialdehyde; GSH: glutathione; NO: nitric oxide.

The bold values represent significant $P<0.05$ while un-bold values represent non-significant $P$ values.

${ }^{*} P$ : significance versus thioacetamide.

** $P$ : significance versus vitamin $C$ and thioacetamide.

${ }^{* * *} P$ : significance versus vitamin $\mathrm{E}$ and thioacetamide. 


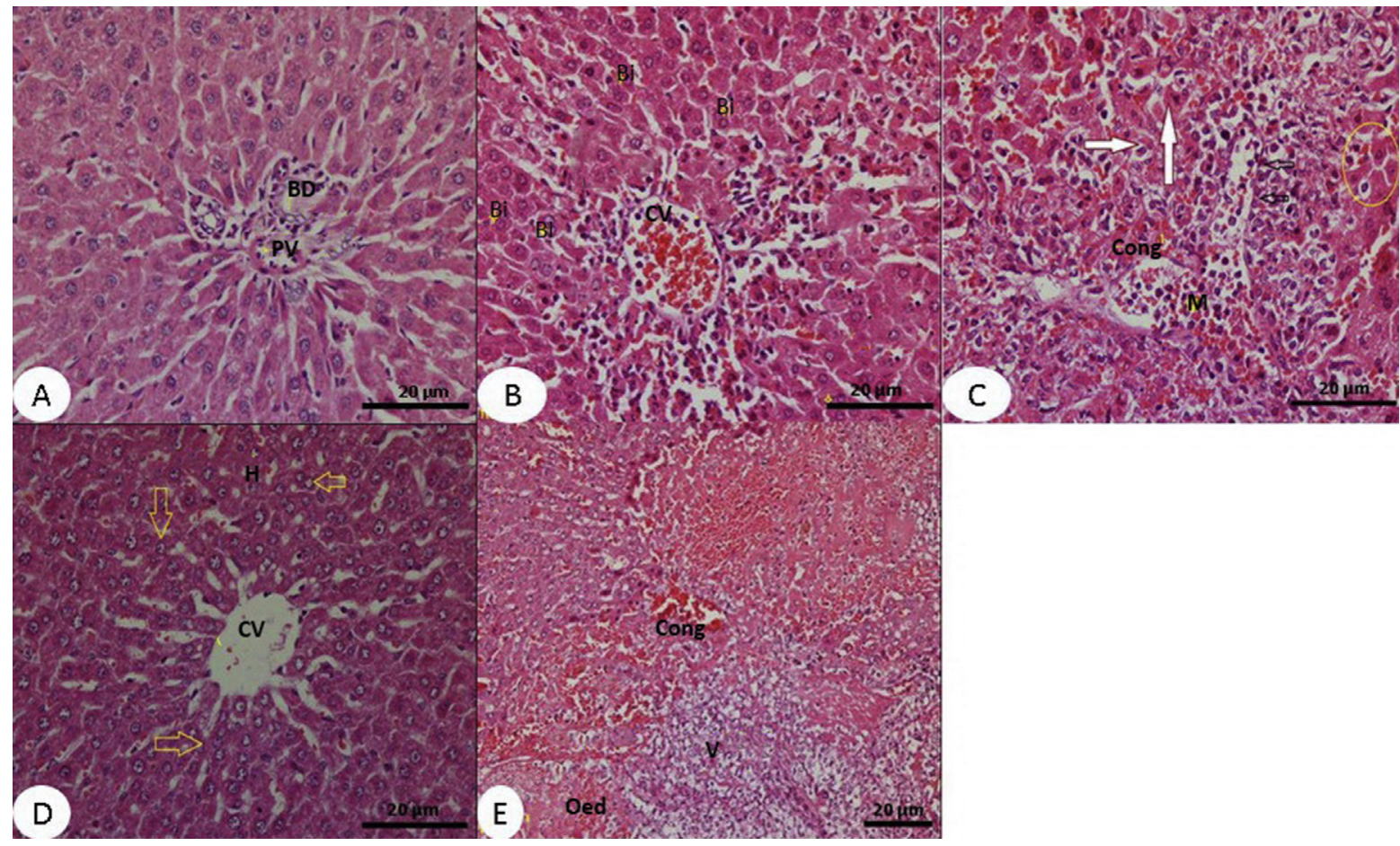

Fig. 1. (A) Photomicrograph from a section of control rat liver showing normal hepatic architecture: the hepatocytes with acidophilic granular cytoplasm and central vesicular nuclei. The portal vein (PV) and the bile ducts (BD) are also seen (H\&E, 400 $\times$ ). (B) Photomicrograph from TAA rats showing acidophilic cytoplasm and binucleated hepatocytes (stars). Notice mononuclear cellular infiltration, hemorrhage $(\mathrm{H})$ and apoptotic hepatocytes (circle) around the congested central vein $(\mathrm{H} \& \mathrm{E}, 400 \times)$. (C) Photomicrograph from a section of liver of TAA rats treated with vitamin C showing the formation of a single layer of short cuboidal epithelial cells (black arrow) forming a layer contact with the mesenchyme lining the portal vein. The hepatocytes in this area revealed coagulative necrosis (white arrow) and apoptosis (circle). The inflammatory cells (M) separated ductular epithelium-like cells and congestion appears at the area. In the central zone, the hepatocytes are intact (Bi) (H\&E, 400 $\times$ ). (D) Photomicrograph from a section of liver of TAA rats treated with vitamin E showing marked regeneration and improvement in hepatic cells around the central vein and prominent improvement around the porta area $(H \& E, 400 \times)$. (E) Photomicrograph from a section of liver of TAA rats treated with a combination of vitamin $C$ and vitamin $E$ showing edema, fibrous tissues, vacuolation and congestion around the portal vein, while the hepatocytes in the central zone are not affected $(\mathrm{H})(\mathrm{H \& E}, 200 \times)$.

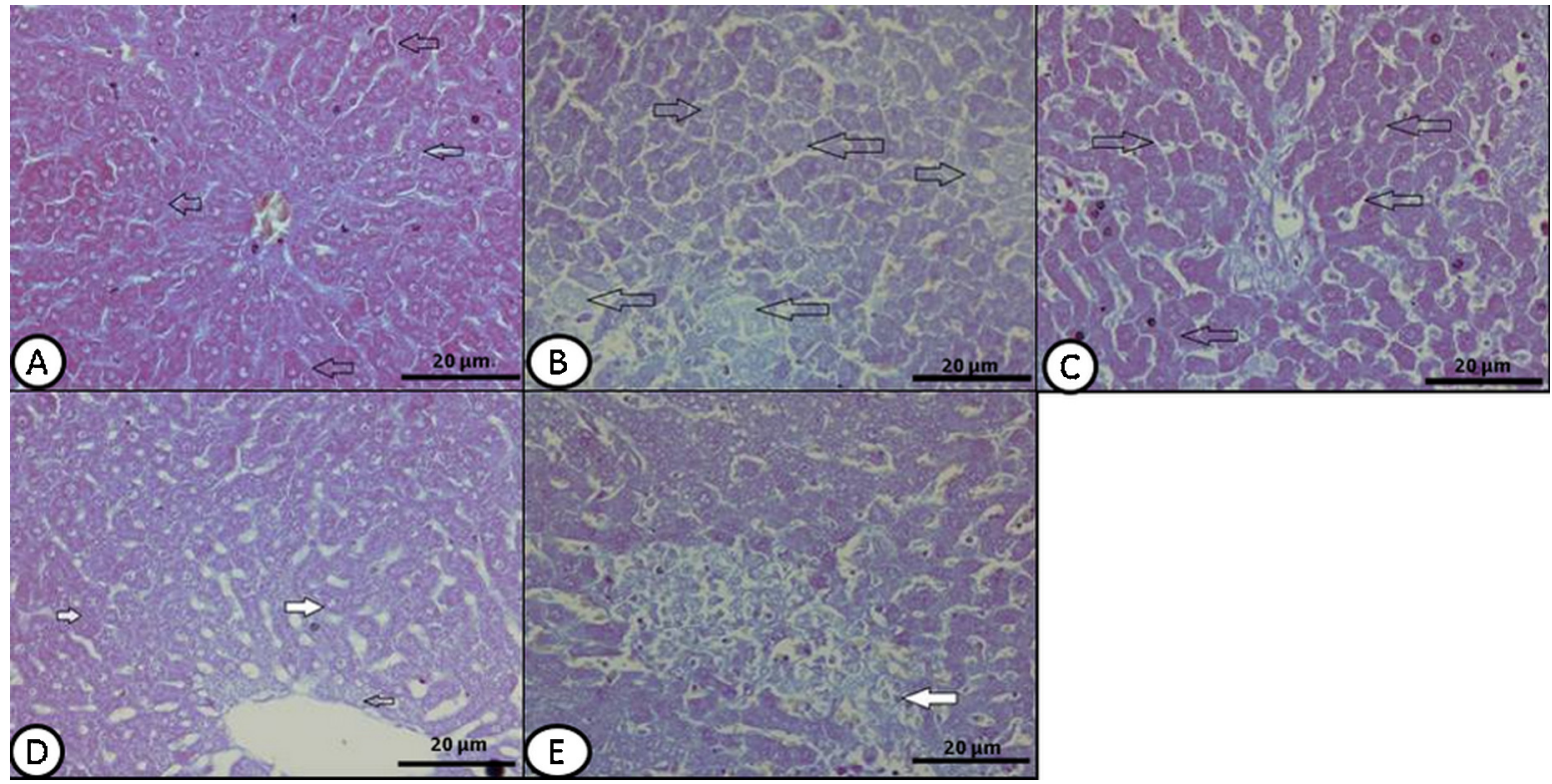

Fig. 2. (A) Photomicrograph from a section of control rat liver showing normal protein distribution in hepatocytes cytoplasm (i.e. normal strong cytoplasmic reactions). (B) Photomicrograph from a section of liver given TAA rats showing marked reduction in protein content especially in damaged areas (i.e. weak reaction). (C) Photomicrograph from a section of liver of TAA rats treated with vitamin C showing moderate to strong reaction (i.e. moderate improvement in protein content in liver cells).(D) Photomicrograph from a section of liver of TAA rats treated with vitamin E showing weak reaction in destroyed cells adjacent central vein (arrow) others cells have positive strong reaction (solid arrow) (i.e. marked improvement of protein content in cytoplasm of hepatic cells is seen). (E) Photomicrograph from a section of liver of TAA rats treated with a combination of vitamin $\mathrm{C}$ and $\mathrm{E}$ showing weak to moderate reaction in destroyed or impacted cells (i.e. moderate improvement in protein content in liver cells) (bromophenol blue reaction, $400 \times)$ 


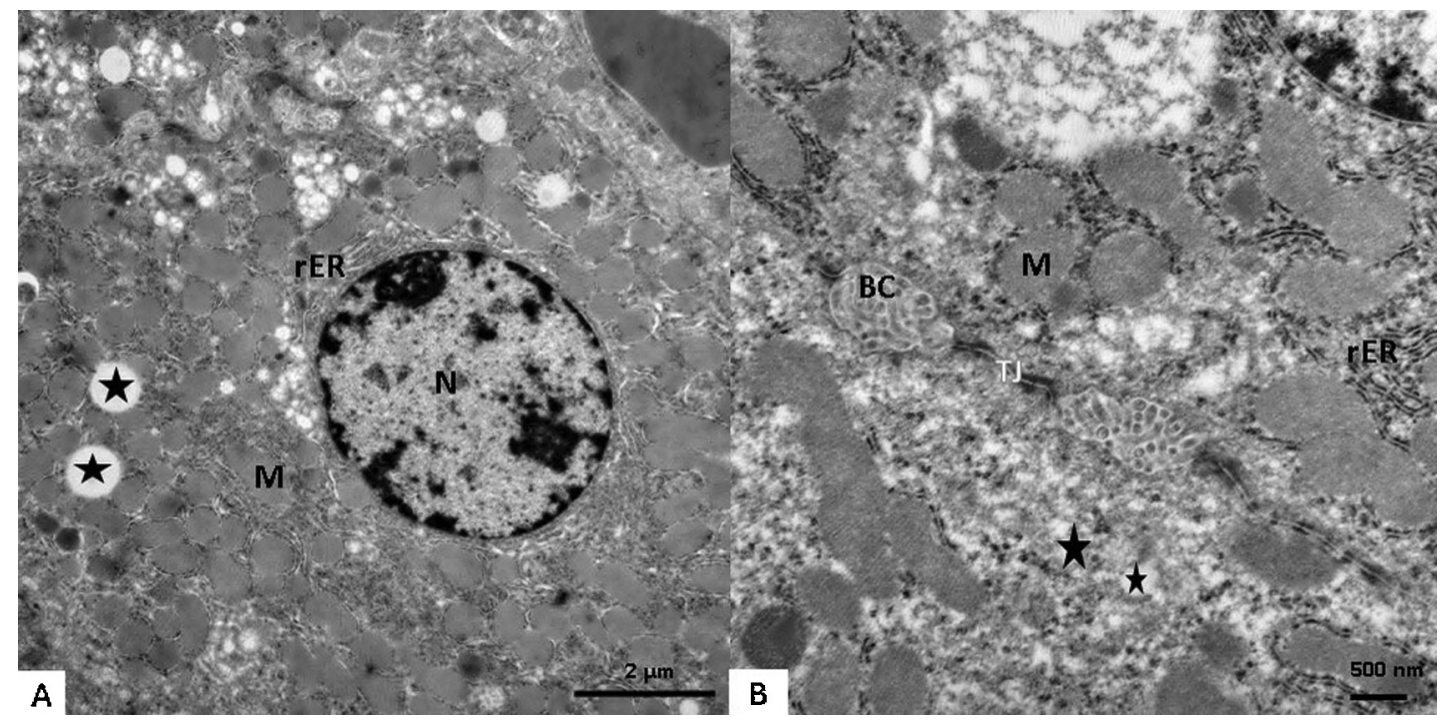

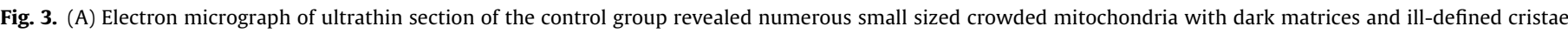

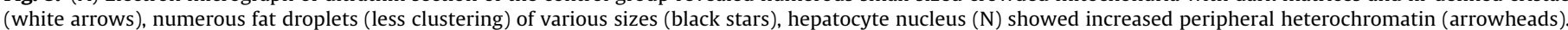

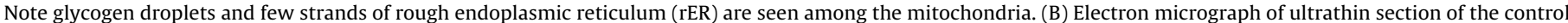

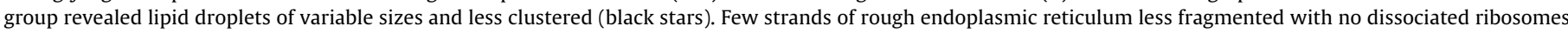

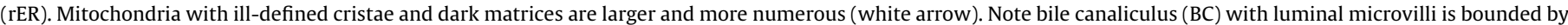
both desmosomes and tight junctions (TJ) (white arrows) (TEM, 5000×).

\subsection{Ultrastructural results of liver specimens}

More detailed exploration of liver structural organization is provided by the electron micrographs; liver of control group revealed hepatocyte presented rounded large central nucleus surrounded by a double membrane envelope interrupted by nuclear pores, dispersed chromatin and prominent nucleoli. Numerous mitochondria either circular or elongated with prominent cristae reside close to RER, plenty of rough endoplasmic reticulum arranged in parallel stacks of flattened cisternae. Furthermore, glycogen inclusions appeared as coarse electron dense granules aggregated in rosette shaped and few lipid droplets were present. Additionally, Bile canaliculi is surrounded by junctional complexes and showing normal microvilli. Hepatocyte disclosed projecting microvilli on the adjacent surfaces, blood sinusoids and phagocytic von Kupffer cells (Fig. 3A and B).

Fine structure of liver of TAA treated group exhibited histopathological alterations referred to cytoplasmic organelles; degenerated hepatocytes, nucleus in some hepatocytes showed loss of normal chromatin pattern with aggregation of clusters of nuclear chromatin at the nuclear envelope, accumulation of many large cytoplasmic vacuoles. Mitochondria become polymorphic, swollen with dramatic modification of their cristae and appearance of electron dense granules within the mitochondria and whorl like myelin figures and cellular debris. There is an increase in RER with fragmented cisternae, drastic glycogen exhaustion become few and scattered, numerous lipid droplets disseminated in the cytoplasm. Moreover, bile canaliculi become dilated with abnormal microvilli. Phagocytic Kupffer cells destructed and blood sinusoids fragmented, apparent decrease of short microvilli from adjacent surfaces of hepatocytes and extensive cytoplasmic degeneration were also observed (Fig. 4A and B).

Furthermore, electron microscopic findings of liver treated with antioxidants and TAA demonstrated hepatocytes regained their normal appearance as their cytoplasm contained vesicular rounded nuclei, homogenous chromatin distribution and prominent nucleoli, surrounded by nuclear envelope and minimal lipid droplet. The hepatocytes revealed reduction in rough endoplasmic reticulum cisternae, glycogen inclusions again occupied the cytoplasm, while the mitochondria were numerous but still damaged and of variable shape and size and laminated membrane arrays were rarely existed. In addition, the hepatocytes regain their healthy bile canaliculi with abundant microvilli and normal junctional complexes, blood sinusoid intact with recovered Kupffer cell. Many short microvilli projecting from adjacent surfaces of hepatocytes were observed. The cytoplasm of the hepatocytes exhibited few vacuoles (Figs. 5-7 $\{\mathrm{A}$ and $\mathrm{B}\}$ ).

\section{Discussion}

Liver plays the main role in metabolism of different nutrients, such as carbohydrates, proteins, and lipids; in addition, it shares in clearance of waste products resulting from metabolism and elimination of exogenous drugs and other xenobioc (Saleem et al., 2010). Increase level of ammonia as result from liver failure is the main etiology of hepatic encephalopathy. Hyperammonemia affect the function of mitochondria, which may result in reduction of ATP synthesis and it enhance free radicals production (Bachmann, 2002).

TAA is considered as a selective hepatotoxin, which is used experimentally to induce hepatic failure. The result of TAA metabolism is highly reactive compound which is thioacetamide$\mathrm{S}$ dioxide; it binds to the tissue macromolecules and may result in hepatic necrosis (Reddy et al., 2004). In this study TAA treatment is accompanied by liver affection which is manifested by increased serum levels of liver enzymes (AST and ALT), triglyceride and cholesterol and decrease in serum levels of total proteins. In addition, oxidative stress is manifested in hepatotoxic rats by increased MDA levels in the homogenate of liver and brain tissues and there are diminution of GSH and NO levels in liver and brain tissues homogenate. Consequently, our study emphasizes that existence of liver failure and brain oxidative stress due to TAA administration, which is in agreement with Bruck et al. (2004).

In accordance with our study, Galisteo et al. (2006) reported that TAA intoxication models registered significantly lower plasma total protein levels compared to healthy models. Moreover, Túnez et al. (2005) reported that TAA reduced the antioxidant status and enhanced lipid peroxidation in liver and brain tissues. Bastway Ahmed et al. (2010) had confirmed the occurrence of oxidative 


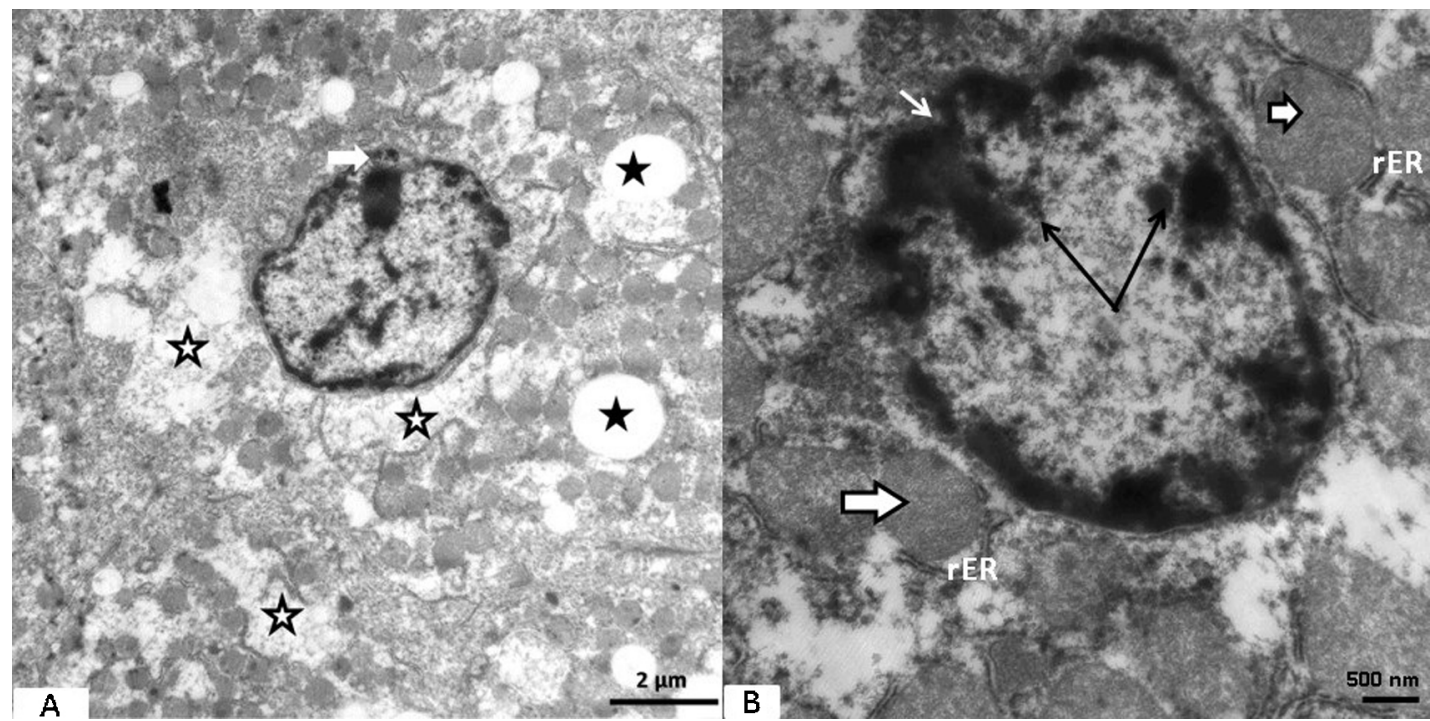

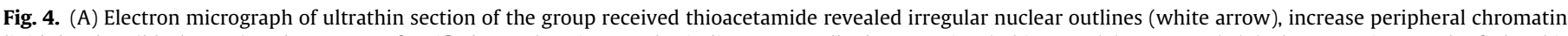

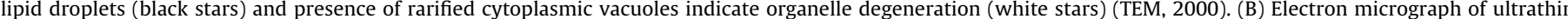

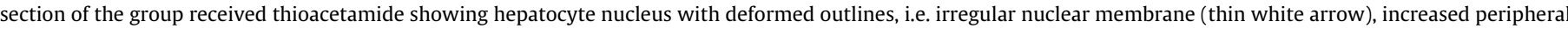

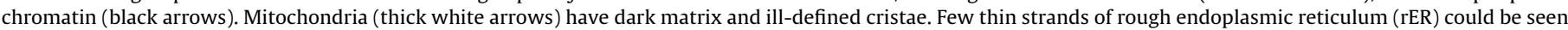
(TEM, 5000 $\times$ )

stress through significant increase of MDA levels and significant decrease of GSH and NO in liver rats as an effect for TAA administration. Aydın et al. (2010) reported that TAA administration resulted in significant increases in plasma transaminase activities as well as hepatic hydroxyproline and lipid peroxide levels, while liver glutathione, superoxide dismutase and glutathione peroxidase protein expressions and activities decreased.

Reddy et al. (2004) confirmed presence of oxidative stress in the cerebral cortex of hyperammonemic and HE animals. Also Sathyasaikumar et al. (2007) reported that they found significant oxidative stress in rats treated with thioacetamide in cerebral cortex, cerebellum, and pons medulla. Moreover, they established that oxidative stress was more distinct in the pons, medulla and cerebral cortex than that present in cerebellum as they found significant increase in the levels of MDA and nitric oxide levels with significant decrease in glutathione ratio and altered antioxidant machinery. In a study for Fadillioglu et al. (2010) had studied the different oxidant and antioxidant parameters on three different parts of brain tissue in thioacetamide-induced HE in this rat model. Then they reported that after thioacetamide injection, there was significant increase in the blood ammonia level and significant increase in ALT and AST activities in TAA administered group compared to the control group. In addition they reported a significant decrease in antioxidant enzyme activities in the cerebral cortex, brain stem and cerebellum. So they reported those protein oxidation and lipid peroxidations were produced in three brain tissue parts. They explained their results by that oxidative injury in the brain tissue are due to increase level blood ammonia (Figs. 8 and 9).

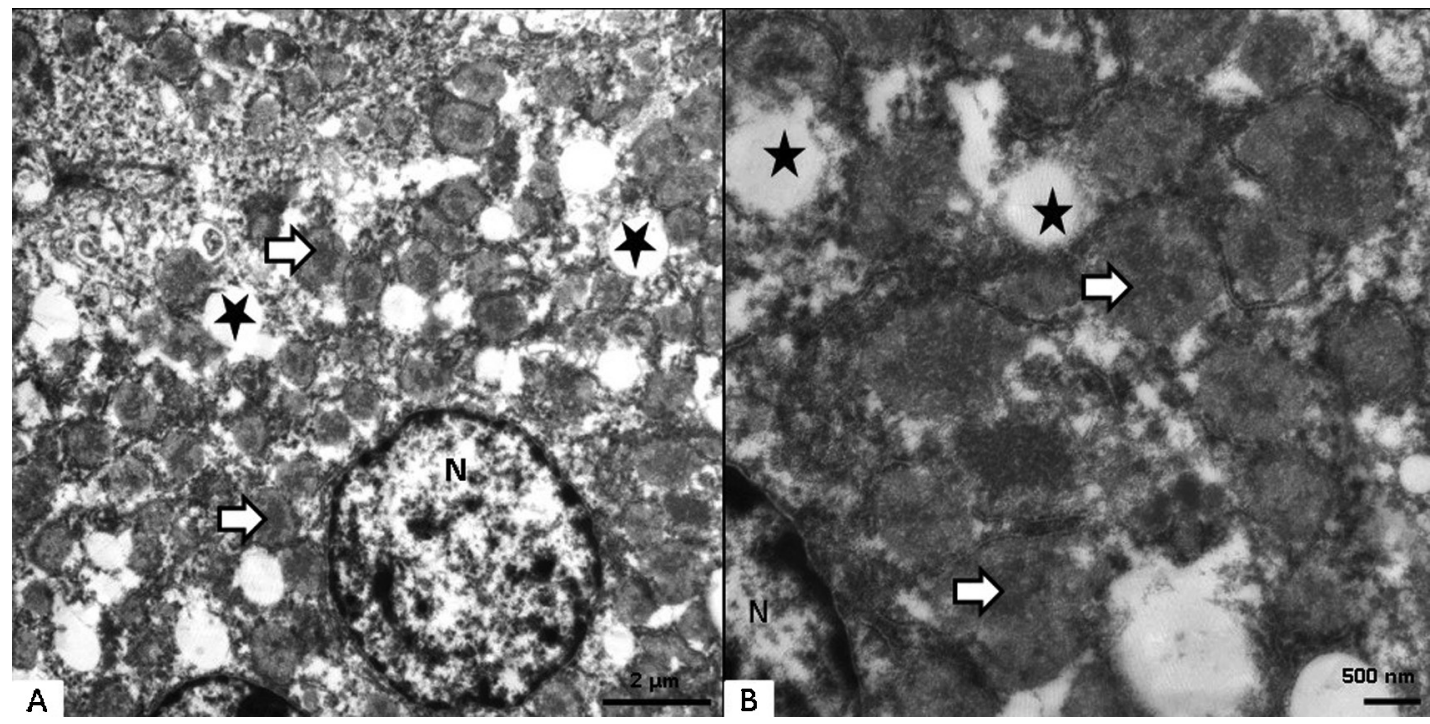

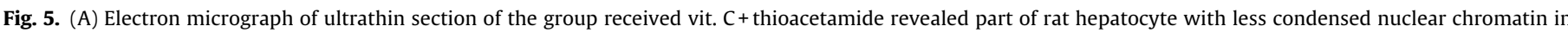

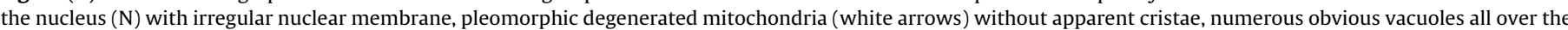

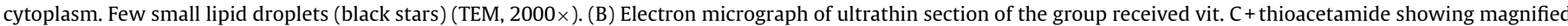

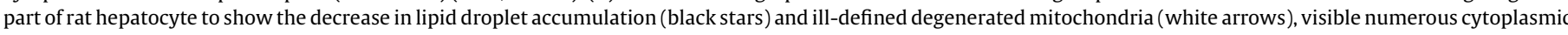
vacuoles (V) (TEM, 5000×). 


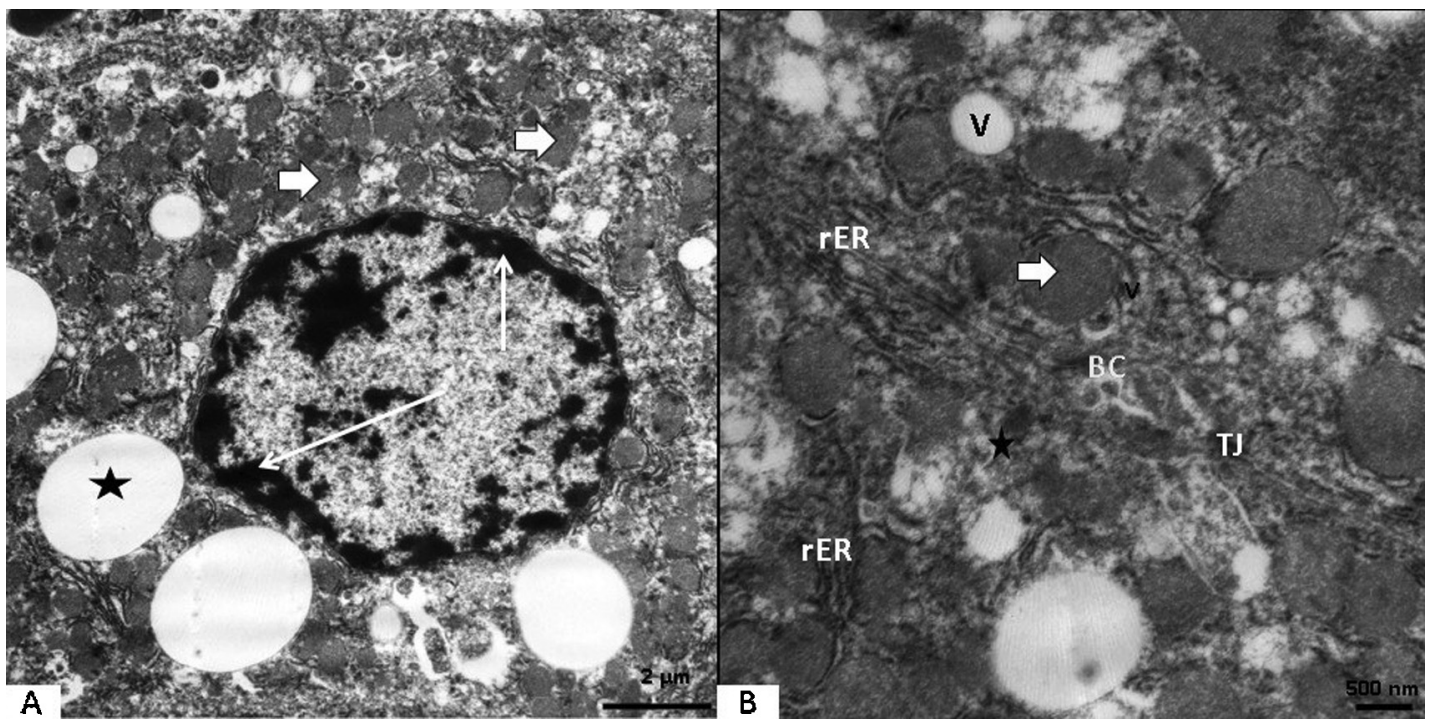

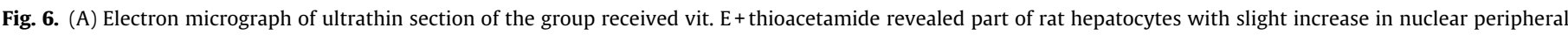

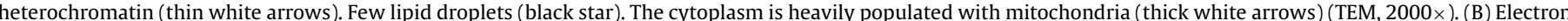

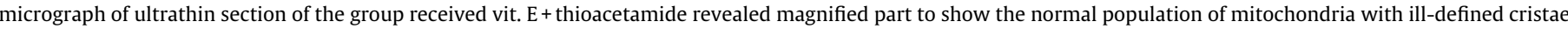

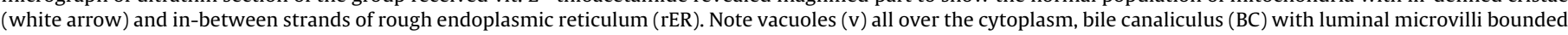
by tight junctions (TJ) (TEM, $5000 \times$ ).

Similar to our findings Al-Attar (2011) reported an elevation in serum lipid triglyceride and cholesterol and liver enzymes, e.g. AST, ALT, and GGT while there was a decrease in serum total protein rats treated with TAA $(300 \mathrm{mg} / \mathrm{kg}$ twice weekly for 10 weeks). The aminotransferases liver enzymes (ALT and AST) are the most frequently used as diagnostic markers for liver cell damage and necrosis. However, ALT is more specific for liver injury than AST which is present in a diversity of different tissues; moreover, ALT is present only in the cytosol while AST present in both the mitochondria and cytosol of hepatocytes (Thapa and Walia, 2007).

In this study, in TAA group, positive correlations were found between ALT with liver-GSH, while negative correlations were found between total protein with brain-GSH and between cholesterol with liver-NO. Treatment with vitamin C led to a positive correlation was found between AST with liver-GSH and treatment with vitamin $\mathrm{E}$ leads to a positive correlation between AST with brain-NO. These findings can be explained by that treatment with TAA led to oxidative stress and elevation in serum liver enzymes that resulted from liver cell necrosis and that led to release of these enzymes to the blood (Gressner et al., 2007) as result of that the body formed more antioxidant as GSH and NO to counterbalanced oxidative stress and remove reactive oxygen species formed (Figs. 10-12).

In accordance with our results, regarding great decrease in serum total protein as results of liver toxicity by TAA (Low et al., 2004) explained this decrease due to defect in RNA processing while the second reported that this reduction in total serum protein

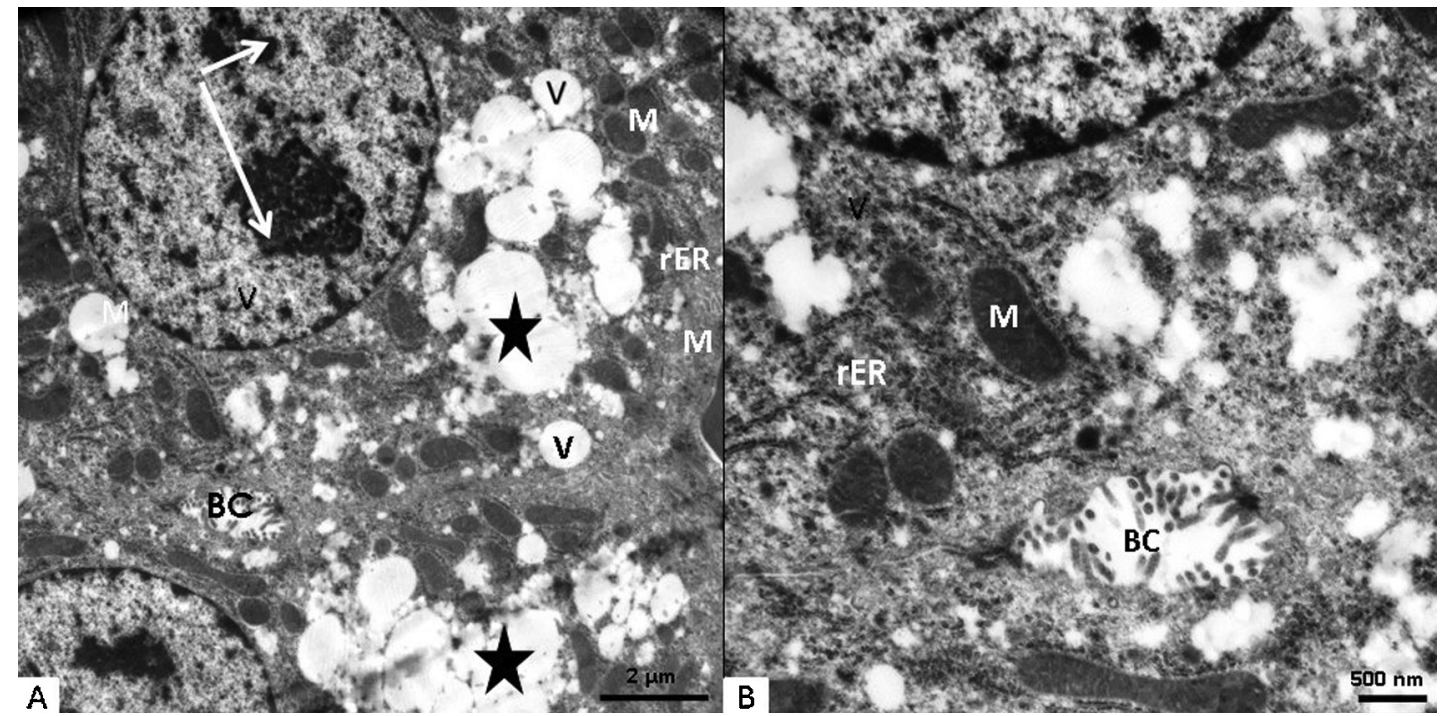

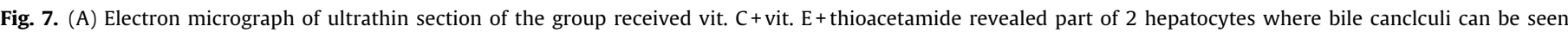

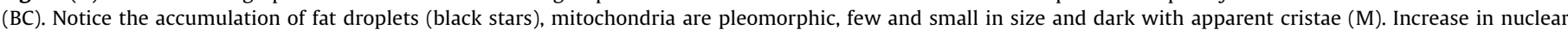

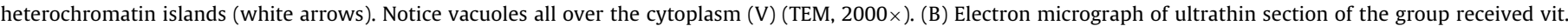

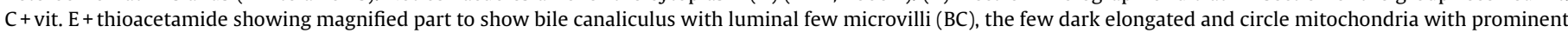
cristae (M), fragmented rER (white stars). Notice cytoplasmi vacuoles of different sizes (V) (TEM, 5000×). 


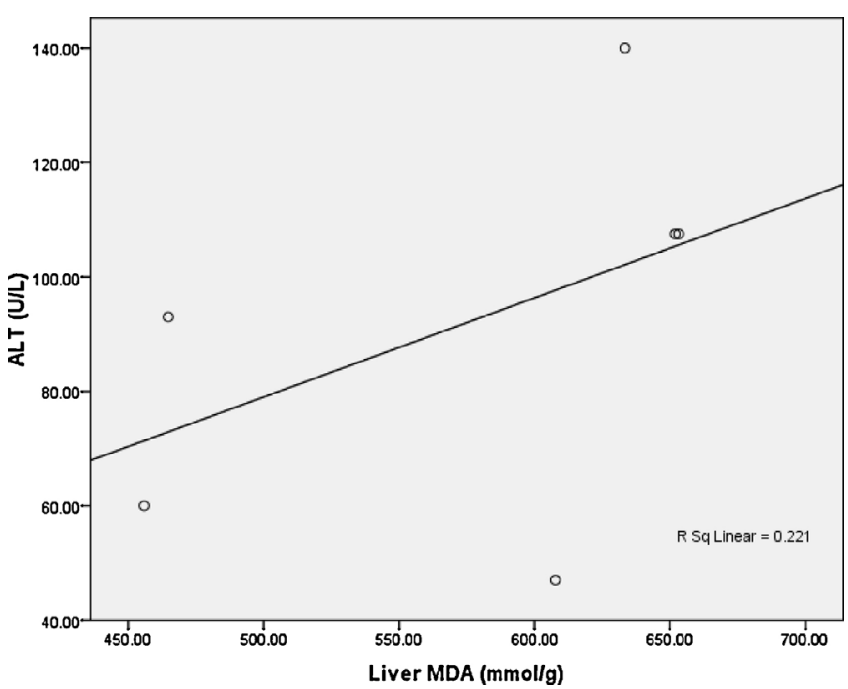

Fig. 8. Scatter chart showed a significant positive correlation between Alanine aminotransferase (ALT) with liver malondialdehyde (MDA) $(r=0.927, P<0.008)$ in control group.

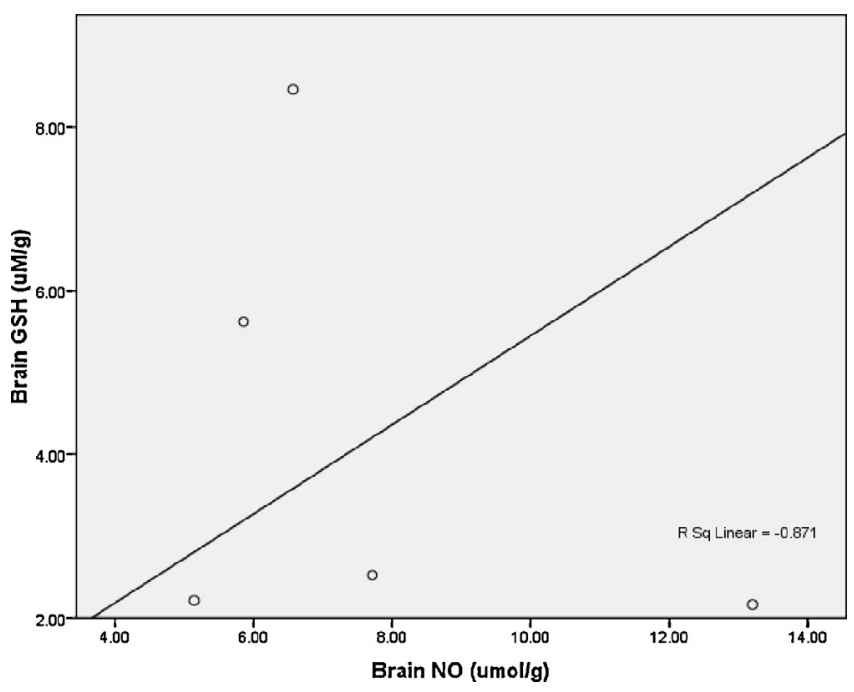

Fig. 9. Scatter chart showed a significant positive correlation between brain glutathione (GSH) with brain nitric oxide (NO) $(r=0.895, P<0.016)$ in control group.

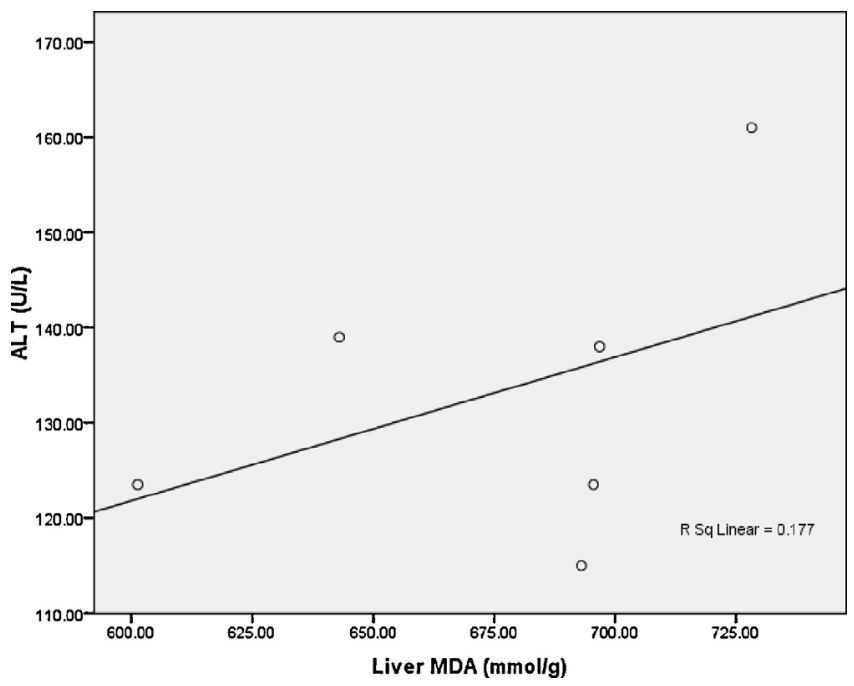

Fig. 10. Scatter chart showed a significant positive correlation between alanine aminotransferase (ALT) with liver malondialdehyde (MDA) $(r=0.850, P<0.032)$ in thioacetamide group.

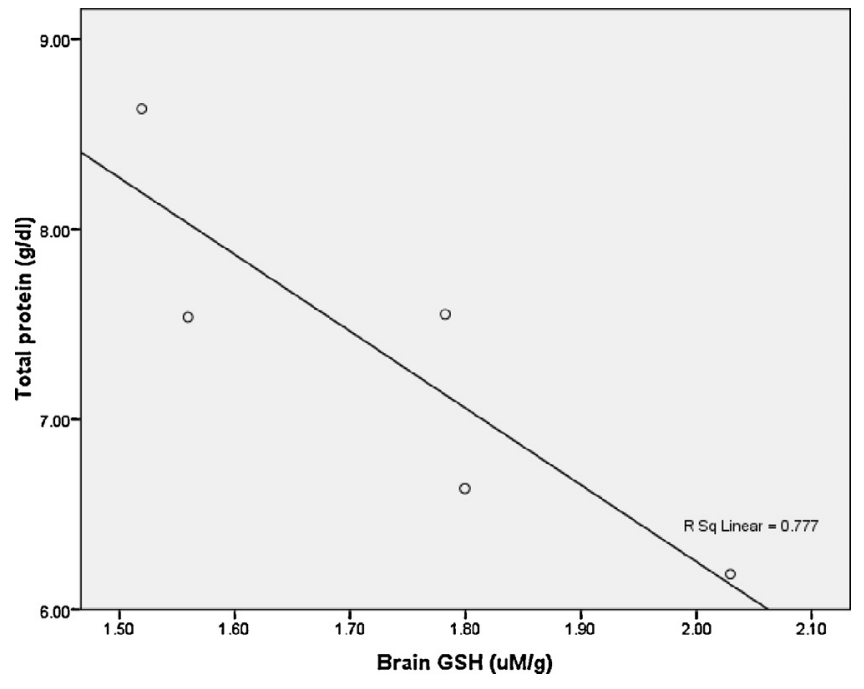

Fig. 11. Scatter chart showed a significant negative correlation between total protein with brain glutathione $(\mathrm{GSH})(r=-0.881, P<0.048)$ in thioacetamide group.

owing to disturbances in carbohydrate, protein, lipid metabolisms due to acute liver intoxication by TAA (Fig. 13).

Thioacetamide administration caused death to some animals during our study. The survival rate of animals in HE group after $24 \mathrm{~h}$ thioacetamide injection was $90 \%$. In Fadillioglu et al. (2010), the survival rate of animals in HE group after $60 \mathrm{~h}$ of thioacetamide injection was 37.5\%. Bruck et al. (1999) demonstrated that the survival rate was $30 \%$ for only thioacetamide and $0.9 \% \mathrm{NaCl}$ solution injected group after $52 \mathrm{~h}$ after first thioacetamide injection, Norton et al. also indicated that female rats lived longer than male rats and all female and male rats were dead $72 \mathrm{~h}$ after thioacetamide injection (Norton et al., 1997) (Fig. 14).

In accordance with the previous studies there are two major factors for induction of $\mathrm{HE}$ which are oxidative damage and increase blood ammonia level. So to prevent HE you have to prevent ROS injury and decreasing blood ammonia level. The nervous system is largely susceptible to oxidative damage because the brain is enriched with polyunsaturated fatty acids (Öztürk et al., 2008). The nervous system also has low level of defense repair mechanisms and very high oxygen consumption against oxidative injury

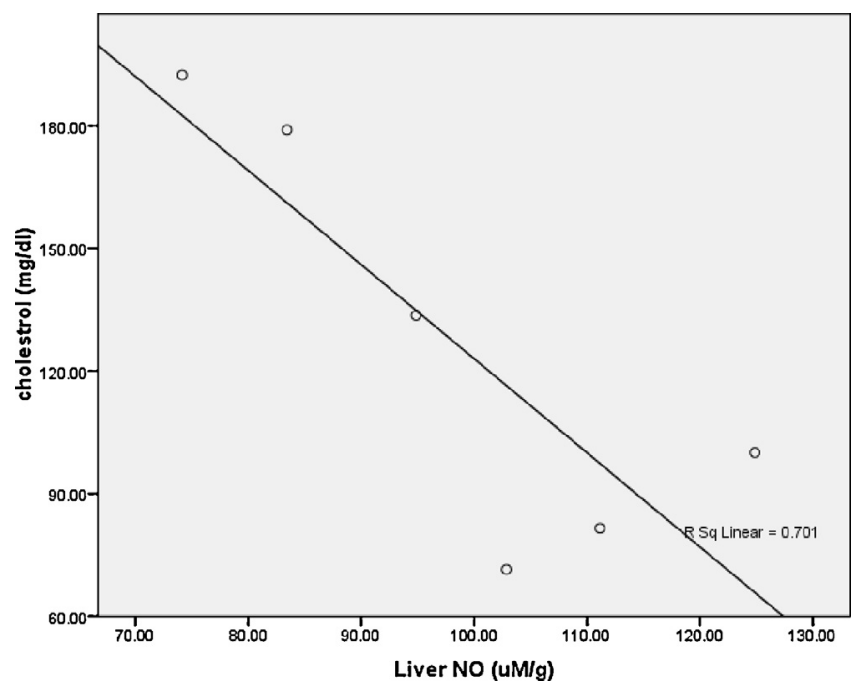

Fig. 12. Scatter chart showed a significant negative correlation between cholesterol and liver nitric oxide $(\mathrm{NO})(r=-0.837, P<0.038)$ in thioacetamide group. 


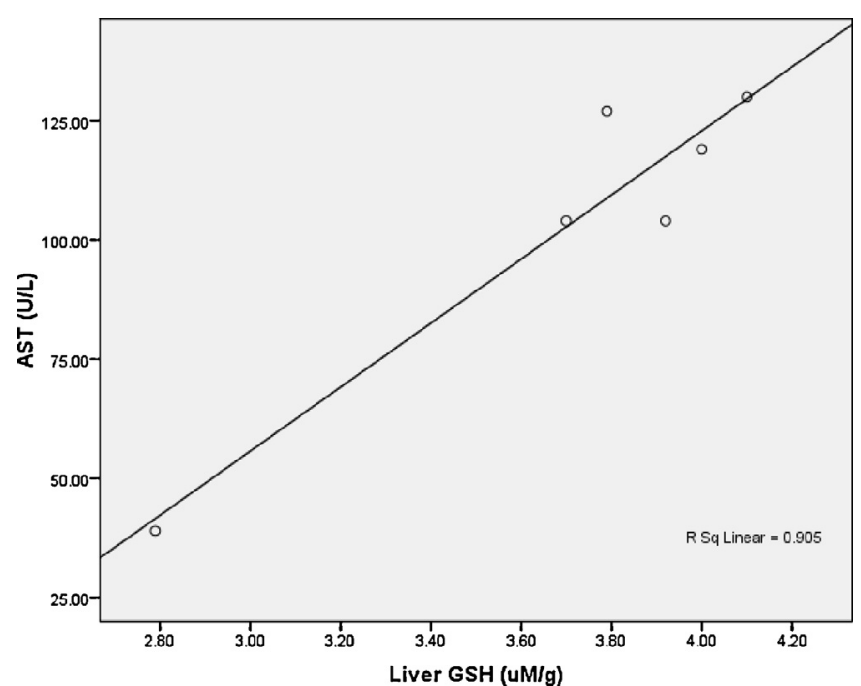

Fig. 13. Scatter chart showed a significant positive correlation between aspartate aminotransferase (AST) with liver glutathione (GSH) $(r=0.951, P<0.004)$ in vitamin $\mathrm{C}$ and thioacetamide group.

(Halliwell et al., 1985). Vitamins C and E are considered the most important endogenous antioxidants due to their exceptional chemical properties which helping them in elimination of different free radicals. The effectiveness of vitamins $\mathrm{C}$ and $\mathrm{E}$ in the treating diseases resulted from long-term exposure to oxidative stress, has been well known (Mayne, 2003). Many authors, reported that TAA treated animals lead to great reduction of their endogenous antioxidants as vitamin C, vitamin E and GSH (Sun et al., 2000) and beneficial effects of antioxidant treatment have been recognized (Bruck et al., 2002) (Fig. 15).

In our study, we reconfirmed that vitamin $C$ and vitamin $E$ played substantial role against the progression of acute hepatic encephalopathy and oxidative stress induced by TAA in rat model. Oral administration of vitamin $C$ in dose of $100 \mathrm{mg} / \mathrm{kg}$ for 3 days and/or vitamin $\mathrm{E}$ in dose of $200 \mathrm{mg} / \mathrm{kg}$ daily for 3 days in acute hepatic injury rat model was accompanied by decrease in serum levels of liver enzymes (AST and ALT), triglyceride and cholesterol and elevation of total proteins. This was accompanied in liver and brain tissue homogenate with decrease of MDA and elevation of

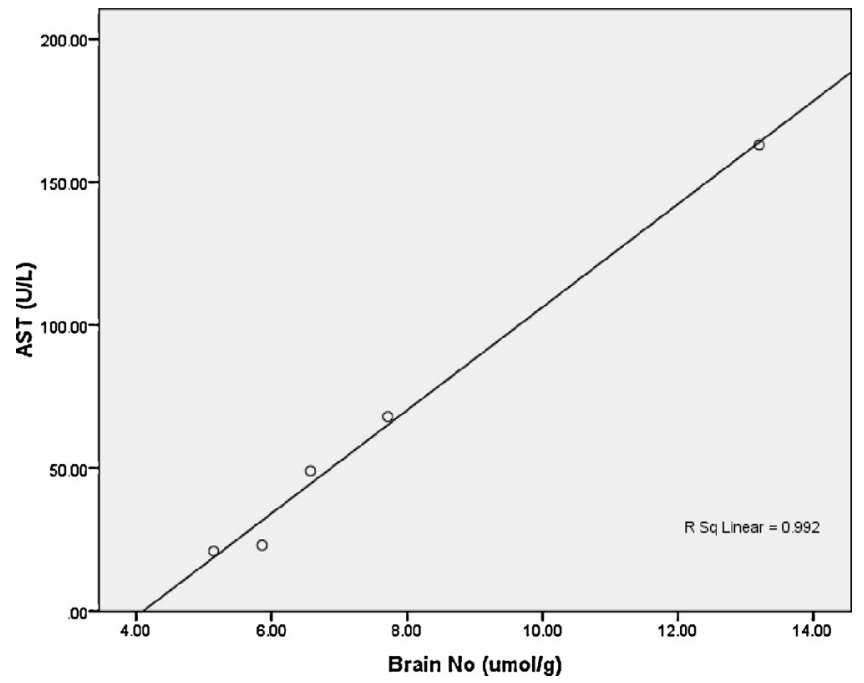

Fig. 14. Scatter chart showed a significant positive correlation between aspartate aminotransferase (AST) with brain nitric oxide (NO) $(r=0.996, P<0.0001)$ in vitamin $\mathrm{E}$ and thioacetamide group.

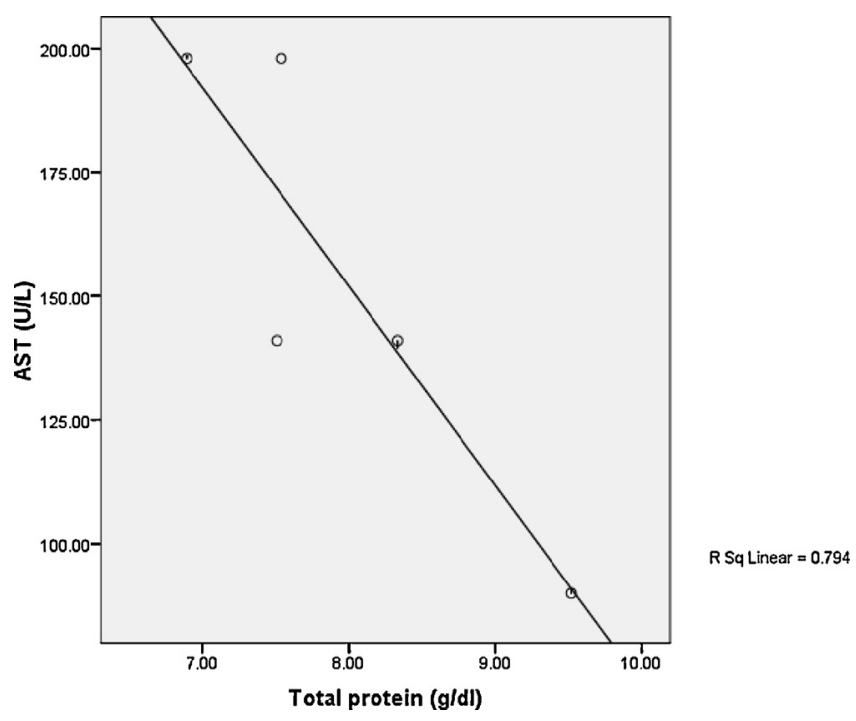

Fig. 15. Scatter chart showed a significant negative correlation between aspartate aminotransferase (AST) with total protein $(r=-0.891, P<0.042)$ in vitamin $\mathrm{C}+$ vitamin $\mathrm{E}+$ thioacetamide group.

GSH and NO. The results of this study also showed that vitamin C administration significantly elevated serum total protein and liver NO. Meanwhile, vitamin E administration was accompanied with decrease serum levels of AST, triglyceride and cholesterol and elevation of brain GSH than vitamin C. Combination of vitamin $\mathrm{C}$ and E administration was accompanied by elevation of liver GSH than when each vitamin administer alone. Hence, our results are similar to other studies that indicated that single or combined treatment of antioxidants; vitamins $\mathrm{E}$ and $\mathrm{C}$; impressively defend liver function against TAA damage (Ming et al., 2006).

Our study in agreement, with different studies showed that the administration of antioxidants like vitamin $\mathrm{E}$ and or vitamin $C$ decrease the severity of hepatic encephalopathy owing to TAA intoxication, indicating that free radicals and reactive oxygen species have an important role in the pathogenesis of hepatic encephalopathy (Velvizhi et al., 2002). Najmi et al. (2010) reported that TAA depleted tissue GSH and increased tissue thiobarbituric acid reactive substances (TBARS) significantly. The post-treatment of animals with L-ornithine-L-aspartate significantly reserved the TAA-induced changes of these oxidative stress markers.

Two key assumptions can be offered to clarify mechanisms of synergistic shielding effects proposed by co-treatment of vitamins E and vitamin C. Primarily, vitamins E and vitamin C possess specific chemical characters which make them can attack and eliminate free radicals produced after TAA administration. TAA intoxication leads to exaggeration in free radical production starting in the mitochondria then rapidly affecting the whole cell leading to disturbance in energy metabolism and membrane transport ending in cell apoptosis and necrosis. Because of the great increase of the free radicals levels the endogenous antioxidants, e.g. vitamin $\mathrm{E}$ and vitamin $\mathrm{C}$ are completely consumed diminishing anti-oxidant power of cells and tissues resulting in sever oxidative injury (Galli et al., 2005; Valko et al., 2006).

Secondly, the interaction between vitamin $\mathrm{E}$ and vitamin $\mathrm{C}$ that results in preserving them in their reduced form which may help in restoring the endogenous antioxidant after being totally exhausted due to TAA intoxication (Fang et al., 2002).

In this respect, Fadillioglu et al. (2010) found that treatment by the laxative and caffeic acid phenethyl ester (CAPE) leading to decrease of levels of MDA, ROS, and nitric oxide levels, increase glutathione much closer to those of control rats in all brain parts. 
However, these reversing effects in the brain stem were not as successful as in other brain parts for catalase activities. They explain the effects of CAPE treatment due to affect mitochondrial function of neurons and also it may to have a role on apoptosis neuronal pathway such as inhibition of caspase-3 and caspase-3independent/p38 (Wei et al., 2008).

The results obtained from this study showed that histological examination of the liver of rats injected with TAA showed massive necrosis associated with degenerative changes including cytoplasmic vacuolation and hydropic degeneration accompanied by cellular infiltration. This agreed with other investigation (Uskoković-Marković et al., 2007) who studied hepatotoxic effects of TAA, they reported that the necrosis becomes more severe and widespread as the time passes and the event is associated with mononuclear cellular infiltration. In addition, they stated that TAA acute toxicity give rise to centrilobular necrosis in liver without fatty change. Other studies discovered that centrilobular necrosis and immense inflammatory reaction after a single dose of TAA was more pronounced with respect to the time factor (Caballero et al., 2001) that coincided with our findings related to TAA treated group.

It was described that mechanism of TAA hepatotoxicity may be that TAA acts as creator of free radicals leading to lipid peroxidation (Shapiro et al., 2006). Moreover, TAA causes increased apoptosis and necrosis, were necrosis become predominant when great doses of TAA were used (Apte et al., 2003). Lately, it was found that the release of hydrolytic enzyme Calpain from dying hepatocytes result in liver cells injury even after cessation of the hepatotoxicant. That led to destruction of the surrounding cells and inflammatory process progress (Limaye et al., 2003).

Moreover, ultrastructural findings of hepatocytes of TAA treated rats shown polymorphic mitochondria with destruction of their cristae, accumulation of electron dense granules, fragmentation of rough endoplasmic reticulum, accumulation of cytoplasmic vacuoles with disturbed nuclear chromatin, slight increase in lipid droplets and loss of short microvilli. Furthermore, these alterations in the cytoplasmic organelles might be due to toxic effects of TAA, which injured protein systems included in the endoplasmic reticulum, those involved in mitochondrial respiration (Fan and Weng, 2005). Additionally, generation of reactive oxygen species caused lipid peroxidation, oxidation of cellular proteins and extensive mitochondrial DNA strand breakage, thus inducing impairment of mitochondrial protein synthesis (Lewis et al., 2001). The ultrastructural changes agreed by other researchers like Faa et al. (1992) who found that TAA toxicity resulted in mitochondrial damage, RER fragmentation, disorganization and dispersion of ribosomes, depletion of the glycogen and finally loss of the microvilli (Pérez et al., 2004; Tasci et al., 2008).

In contrast, the ultrastructural picture of liver received antioxidants and thioacetamide revealed a round nucleus and nucleolus with clear nuclear envelope, dispersed chromatin masses and minimal lipid droplets with an undamaged rough endoplasmic reticulum but the mitochondria were still impaired without deposits. As well, the hepatocytes exhibited a healthy bile canalicului with normal microvilli and intact junctional complexes. The blood sinusoid was unharmed with a healthy Kupffer cell. The improvement is more obvious with vitamin $\mathrm{E}$, which assisted to enhance the antioxidant defense system (Kirimlioglu et al., 2006).

It has been revealed by many authors that antioxidants, such as vitamin E (Honegger et al., 1995) and the vitamin C (Vereckei et al., 1993) or their combination when administered in liver injury, led to decrease the pathological lysosomes in number and in size (Allan Butterfield et al., 2002). However, this did not wholly preclude myelin figures creation or electron dense deposits (Al-Kahtani, 2010). Bansal et al. (2005) disclosed that the hepatocytes were nearly normal, with minimal necrosis and proved that the cotreatment with vitamin $\mathrm{E}$ and $\mathrm{C}$ diminished the degree of oxidative stress in a time-dependent manner. The mitochondria still affected and degenerated and this might be due to that mitochondria were the most sensitive and target organelle attacked by TAA. It was reported that exposure of rats to oxidants like TAA, increased the production of many cytokines as nitric oxide synthase-2, cyclooxygenase- 2 and tumor necrosis factor alpha (TNF- $\alpha$ ) by the activated Kupffer cell and injured hepatocytes (Wang et al., 2004).

Therefore, that vitamin $\mathrm{C}$ and $\mathrm{E}$ may play a role in interfere with release of that inflammatory mediators (cytokines) or inhibiting their activity in injured hepatocytes (Karabay et al., 2005). Moreover, vitamin $\mathrm{C}$ and $\mathrm{E}$ act as an antioxidant in vivo and in vitro studies (Timbrell et al., 1995). The mechanisms of the possible antioxidant effects are the ability to suppress lipid peroxidation (Dorğru-Abbasoğlu et al., 2001). In addition, vitamin C and E not only inhibit hepatocellular degeneration, necrosis and DNA damage, but also inhibit the lesions in the extracellular matrix induced (Zhou et al., 1996).

\section{Conclusions}

In conclusion, the results of this study suggest that: (i) TAA encourages both liver and brain oxidative stress, together with acute hepatic failure; (ii) Brain and hepatic oxidative stress can be protected by vitamin $\mathrm{C}$ and vitamin $\mathrm{E}$ and/or their combination; (iii) vitamin $\mathrm{C}$ and vitamin $\mathrm{E}$ and their combination protect against liver and brain damage. Treatment with vitamin $\mathrm{E}$ is more effective than vitamin $C$ in protection of the liver and increase brain-GSH while vitamin $C$ is effective in elevation of liver-NO than vitamin $C$. This can be explained by decrease levels of GSH leads to defect in function of vitamin $C$ as antioxidant. In addition, antioxidants especially vitamin $\mathrm{E}$ administration led to decrease in the histologic as well as ultrastructural changes in the parenchyma of rat liver. These data indicate the valuable effect of antioxidant agents, particularly vitamin $\mathrm{E}$, against oxidative stress and hepatic and brain illnesses induced by TAA, as well as its potential usage in the management of liver injury and hepatic encephalopathy persuaded by fulminant hepatic failure.

\section{Authors' contributions}

All authors participated in the design of this work and performed equally. All authors read and approved the final manuscript.

\section{Conflict of interest statement}

The authors declare that they have no conflict of interest.

\section{Acknowledgement}

The authors thank the Deanship of Scientific Research (DSR), King Abdulaziz University for the research grant (14-140-D1432).

\section{References}

Al-Attar, A.M., 2011. Hepatoprotective influence of vitamin C on thioacetamideinduced liver cirrhosis in wister male rats. J. Pharmacol. Toxicol. 6, 218-233.

Al-Kahtani, M.A., 2010. Renal damage mediated by oxidative stress in mice treated with aluminium chloride: protective effects of taurine. J. Biol. Sci. 10, 584-595.

Allan Butterfield, D., Castegna, A., Drake, J., Scapagnini, G., Calabrese, V., 2002. Vitamin $\mathrm{E}$ and neurodegenerative disorders associated with oxidative stress. Nutr. Neurosci. 5, 229-239.

Apte, U.M., Limaye, P.B., Desaiah, D., Bucci, T.J., Warbritton, A., Mehendale, H.M. 2003. Mechanisms of increased liver tissue repair and survival in diet-restricted rats treated with equitoxic doses of thioacetamide. Toxicol. Sci. 72, 272-282.

Avraham, Y., Israeli, E., Gabbay, E., Okun, A., Zolotarev, O., Silberman, I., Ganzburg, V., Dagon, Y., Magen, I., Vorobia, L., Pappo, O., Mechoulam, R., Ilan, Y., Berry, E.M., 2006. Endocannabinoids affect neurological and cognitive function in thioacetamide-induced hepatic encephalopathy in mice. Neurobiol. Dis. 21, $237-245$. 
Aydın, A.F., Küskü-Kiraz, Z., Doğru-Abbasoğlu, S., Güllüoğlu, M., Uysal, M., KoçakToker, N., 2010. Effect of carnosine against thioacetamide-induced liver cirrhosis in rat. Peptides 31, 67-71.

Bachmann, C., 2002. Mechanisms of hyperammonemia. Clin. Chem. Lab. Med. 40 653-662.

Bansal, A.K., Bansal, M., Soni, G., Bhatnagar, D., 2005. Protective role of Vitamin E pre-treatment on $\mathrm{N}$-nitrosodiethylamine induced oxidative stress in rat liver. Chem. Biol. Interact. 156, 101-111.

Bradford, M.M., 1976. A rapid and sensitive method for the quantitation of microgram quantities of protein utilizing the principle of protein-dye binding. Anal Biochem. 72, 248-254.

Bass, N., 2007. Review article: the current pharmacological therapies for hepatic encephalopathy. Aliment. Pharmacol. Ther. 25, 23-31.

Bastway Ahmed, M., Hasona, N., Selemain, A., 2010. Protective effects of extract from dates (Phoenix dactylifera L.) and ascorbic acid on thioacetamide-induced hepatotoxicity in rats. Iran. J. Pharm. Res. 7, 193-201.

Beutler, E., Duron, O., Kelly, B.M., 1963. Improved method for the determination of blood glutathione. J. Lab. Clin. Med. 61, 882-888.

Blatt, D.H., Leonard, S.W., Traber, M.G., 2001. Vitamin E kinetics and the function of tocopherol regulatory proteins. Nutrition 17, 799-805.

Bruck, R., Aeed, H., Shirin, H., Matas, Z., Zaidel, L., Avni, Y., Halpern, Z., 1999. The hydroxyl radical scavengers dimethylsulfoxide and dimethylthiourea protect rats against thioacetamide-induced fulminant hepatic failure. J. Hepatol. 31, 27-38.

Bruck, R., Genina, O., Aeed, H., Alexiev, R., Nagler, A., Avni, Y, Pines, M. 2001. Halofuginone to prevent and treat thioacetamide-induced liver fibrosis in rats. Hepatology 33, 379-386.

Bruck, R., Aeed, H., Schey, R., Matas, Z., Reifen, R., Zaiger, G., Hochman, A., Avni, Y., 2002. Pyrrolidine dithiocarbamate protects against thioacetamide-induced fulminant hepatic failure in rats. J. Hepatol. 36, 370-377.

Bruck, R., Aeed, H., Avni, Y., Shirin, H., Matas, Z., Shahmurov, M., Avinoach, I., Zozulya, G., Weizman, N., Hochman, A., 2004. Melatonin inhibits nuclear factor kappa B activation and oxidative stress and protects against thioacetamide induced liver damage in rats. J. Hepatol. 40, 86-93.

Caballero, M.E., Berlanga, J., Ramirez, D., Lopez-Saura, P., Gozalez, R., Floyd, D.N., Marchbank, T., Playford, R.J., 2001. Epidermal growth factor reduces multiorgan failure induced by thioacetamide. Gut $48,34-40$.

Dorğru-Abbasoğlu, S., Kanbağli, Ö., Balkan, J., Çevikbaş, U., Aykaç-Tokerl, G., Uysall, M., 2001. The protective effect of taurine against thioacetamide hepatotoxicity of rats. Hum. Exp. Toxicol. 20, 23-27.

Ellman, G.L., 1959. Tissue sulfhydryl groups. Arch. Biochem. Biophys. 82, 70-77.

Faa, G., Ambu, R., Congiu, T., Costa, V., Ledda-Columbano, G.M., Coni, P., Curto, M., Giacomini, L., Columbano, A., 1992. Early ultrastructural changes during thioacetamide-induced apoptosis in rat liver. J. Submicr. Cytol. Pathol. 24, 417-424.

Fadillioglu, E., Gursul, C., Iraz, M., 2010. Effects of caffeic acid phenethyl ester on thioacetamide-induced hepatic encephalopathy in rats. Progr. NeuroPsychopharmacol. Biol. Psychiatr. 34, 1440-1445.

Fan, S., Weng, C.-F., 2005. Co-administration of cyclosporine an alleviates thioacetamide-induced liver injury. World J. Gastroenterol. 11, 1411-1419.

Fang, Y.Z., Yang, S., Wu, G., 2002. Free radicals, antioxidants, and nutrition. Nutrition $18,872-879$.

Galisteo, M., Suarez, A, Montilla, M., Fernandez, M., Gil, A, Navarro, M., 2006 Protective effects of Rosmarinus tomentosus ethanol extract on thioacetamideinduced liver cirrhosis in rats. Phytomedicine 13, 101-108.

Galli, F., Piroddi, M., Annetti, C., Aisa, C., Floridi, E., Floridi, A., 2005. Oxidative stress and reactive oxygen species. Contrib. Nephrol. 149, 240-260.

Goldbarg, J.A., Friedman, O.M., Pineda, E.P., Smith, E.E., Chatterji, R., Stein, E.H., Rutenburg, A.M., 1960. The colorimetric determination of gamma-glutamyl transpeptidase with a synthetic substrate. Arch. Biochem. Biophys. 91, 61-70.

Gressner, O.A., Weiskirchen, R., Gressner, A.M., 2007. Biomarkers of liver fibrosis: clinical translation of molecular pathogenesis or based on liver-dependent malfunction tests. Clin. Chim. Acta 381, 107-113.

Halliwell, B., Gutteridge, J., Blake, D., Ward, R.J., May, P., Sies, H., 1985. Metal ions and oxygen radical reactions in human inflammatory joint disease [and discussion]. Philos. Trans. R. Soc. Lond. B, Biol. Sci. 311, 659-671.

Honegger, U.E., Scuntaro, I., Wiesmann, U.N., 1995. Vitamin E reduces accumulation of amiodarone and desethylamiodarone and inhibits phospholipidosis in cultured human cells. Biochem. Pharmacol. 49, 1741-1745.

Karabay, G., Aldemir, D., Akin, E., Ogus, E., Gur, G., Boyacioglu, S., Turkoglu, S., 2005 The effect of melatonin treatment on oxidative and nitrosative stress in rats with thioacetamide-induced hepatic damage. Hepatol. Res. 31, 160-167.

Kirimlioglu, V., Kirimlioglu, H., Yilmaz, S., Ozgor, D., Coban, S., Karadag, N., Yologlu, S 2006. Effect of Fish Oil, Olive Oil, and Vitamin E on Liver Pathology, Cell Proliferation, and Antioxidant Defense System in Rats Subjected to Partial Hepatectomy Transplantation Proceedings. Elsevier, pp. 564-567.

Lewis, W., Copeland, W.C., Day, B.J., 2001. Mitochondrial DNA depletion, oxidative stress, and mutation: mechanisms of dysfunction from nucleoside reverse transcriptase inhibitors. Lab. Invest. 81, 777-790.

Limaye, P.B., Apte, U.M., Shankar, K., Bucci, T.J., Warbritton, A., Mehendale, H.M. 2003. Calpain released from dying hepatocytes mediates progression of acute liver injury induced by model hepatotoxicants. Toxicol. Appl. Pharmacol. 191, 211-226.

Lizardi-Cervera, J., Almeda, P., Guevara, L., Uribe, M., 2003. Hepatic encephalopathy: a review. Ann. Hepatol. 2, 122-130.
Low, T.Y., Leow, C.K., Salto-Tellez, M., Chung, M.C., 2004. A proteomic analysis of thioacetamide-induced hepatotoxicity and cirrhosis in rat livers. Proteomics 4 , 3960-3974.

Mayne, S.T., 2003. Antioxidant nutrients and chronic disease: use of biomarkers of exposure and oxidative stress status in epidemiologic research. J. Nutr. 133, 933S-940S.

Mazia, D., Brewer, P.A., Alfert, M., 1953. The cytochemical staining and measurement of protein with mercuric bromphenol blue. Biol. Bull. 104, 57-67.

McDonough, K.H., 2003. Antioxidant nutrients and alcohol. Toxicology 189, 89-97.

Mihara, M., Uchiyama, M., 1978. Determination of malonaldehyde precursor in tissues by thiobarbituric acid test. Anal. Biochem. 86, 271-278.

Ming, Z., Fan, Y., Yang, X., Wayne Lautt, W., 2006. Synergistic protection by $\mathrm{S}$-adenosylmethionine with vitamins $\mathrm{C}$ and $\mathrm{E}$ on liver injury induced by thioacetamide in rats. Free Radic. Biol. Med. 40, 617-624.

Miranda, K.M., Espey, M.G., Yamada, K., Krishna, M., Ludwick, N., Kim, S., Jourd'heuil, D., Grisham, M.B., Feelisch, M., Fukuto, J.M., Wink, D.A., 2001. Unique oxidative mechanisms for the reactive nitrogen oxide species, nitroxyl anion. J. Biol. Chem. 276, 1720-1727.

Najmi, A.K., Pillai, K.K., Pal, S.N., Akhtar, M., Aqil, M., Sharma, M., 2010. Effect of L-ornithine L-aspartate against thioacetamide-induced hepatic damage in rats. Indian J. Pharmacol. 42, 384-387.

Norton, N.S., McConnell, J.R., Rodriguez-Sierra, J.F., 1997. Behavioral and physiological sex differences observed in an animal model of fulminant hepatic encephalopathy in the rat. Physiol. Behav. 62, 1113-1124.

Öztürk, E., Demirbilek, S., Köroğlu, A., But, A., Begeç, Z.Ö., Gülec, M., Akyol, Ö., Ersoy, M.Ö., 2008. Propofol and erythropoietin antioxidant properties in rat brain injured tissue. Progr. Neuro-Psychopharmacol. Biol. Psychiatr. 32, 81-86.

Pawa, S., Ali, S., 2004. Liver necrosis and fulminant hepatic failure in rats: protection by oxyanionic form of tungsten. Biochim. Biophys. Acta 1688, 210-222.

Pérez, M.J., Sánchez-Medina, F., Torres, M., Gil, A., Suárez, A., 2004. Dietary nucleotides enhance the liver redox state and protein synthesis in cirrhotic rats. J. Nutr. 134, 2504-2508.

Raghavan, M., Marik, P.E., 2006. Therapy of intracranial hypertension in patients with fulminant hepatic failure. Neurocrit. Care 4, 179-189.

Reddy, P., Murthy, C.R., Reddanna, P., 2004. Fulminant hepatic failure induced oxidative stress in nonsynaptic mitochondria of cerebral cortex in rats. Neurosci. Lett. 368, 15-20.

Reitman, S., Frankel, S., 1957. A colorimetric method for the determination of serum glutamic oxalacetic and glutamic pyruvic transaminases. Am. J. Clin. Pathol. 28, 56-63.

Reynolds, E.S., 1963. The use of lead citrate at high $\mathrm{pH}$ as an electron-opaque stain in electron microscopy. J. Cell Biol. 17, 208-212.

Saleem, T.S.M., Chetty, C.M., Ramkanth, S., Rajan, V., Kumar, K.M., Gauthaman, K., 2010. Hepatoprotective herbs-a review. Int. J. Res. Pharm. Sci. 1, 1-5.

Sathyasaikumar, K., Swapna, I., Reddy, P., Murthy, C.R., Gupta, A.D., Senthilkumaran, B., Reddanna, P., 2007. Fulminant hepatic failure in rats induces oxidative stress differentially in cerebral cortex, cerebellum and pons medulla. Neurochem. Res. $32,517-524$.

Shapiro, H., Ashkenazi, M., Weizman, N., Shahmurov, M., Aeed, H., Bruck, R., 2006. Curcumin ameliorates acute thioacetamide-induced hepatotoxicity. J. Gastroenterol. Hepatol. 21, 358-366.

Singh, R.P. Sharad, S., Kapur, S., 2004. Free radicals and oxidative stress in neurodegenerative diseases: relevance of dietary antioxidants. J. Ind. Acad. Clin. Med. 5, $218-225$.

Sun, F., Hayami, S., Ogiri, Y., Haruna, S., Tanaka, K., Yamada, Y., Tokumaru, S., Kojo, S., 2000. Evaluation of oxidative stress based on lipid hydroperoxide, vitamin $\mathrm{C}$ and vitamin E during apoptosis and necrosis caused by thioacetamide in rat liver. Biochim. Biophys. Acta 1500, 181-185.

Tasci, I., Mas, N., Mas, M.R., Tuncer, M., Comert, B., 2008. Ultrastructural changes in hepatocytes after taurine treatment in $\mathrm{CCl} 4$ induced liver injury. World J. Gastroenterol. 14, 4897

Thapa, B., Walia, A., 2007. Liver function tests and their interpretation. Indian J. Pediatr. 74, 663-671.

Timbrell, J., Seabra, V., Water, eld, C., 1995. The in vivo and in vitro protective properties of taurine. Gen. Pharmacol. 26, 453-462.

Túnez, I., Muñoz, M.C., Villavicencio, M.A., Medina, F.J., de Prado, E.P., Espejo, I., Barcos, M., Salcedo, M., Feijóo, M., Montilla, P., 2005. Hepato- and neurotoxicity induced by thioacetamide: protective effects of melatonin and dimethylsulfoxide. Pharmacol. Res. 52, 223-228.

Uskoković-Marković, S., Milenković, M., Topić, A., Kotur-Stevuljević, J., Stefanović, A., Antić-Stanković, J., 2007. Protective effects of tungstophosphoric acid and sodium tungstate on chemically induced liver necrosis in wistar rats. J. Pharm. Pharm. Sci. 10, 340-349.

Valko, M., Rhodes, C., Moncol, J., Izakovic, M., Mazur, M., 2006. Free radicals, metals and antioxidants in oxidative stress-induced cancer. Chem. Biol. Interact. 160, $1-40$.

Velvizhi, S., Dakshayani, K.B., Subramanian, P., 2002. Effects of alpha-ketoglutarate on antioxidants and lipid peroxidation products in rats treated with ammonium acetate. Nutrition $18,747-750$.

Vereckei, A., Blazovics, A., Gyorgy, I., Feher, E., Toth, M., Szenasi, G., Zsinka, A., Foldiak, G., Feher, J., 1993. The role of free radicals in the pathogenesis of amiodarone toxicity. J. Cardiovasc. Electrophysiol. 4, 161-177.

Wang, C.H., Chen, Y.J., Lee, T.H., Chen, Y.S., Jawan, B., Hung, K.S., Lu, C.N., Liu, J.K., 2004. Protective effect of MDL28170 against thioacetamide-induced acute liver failure in mice. J. Biomed. Sci. 11, 571-578. 
Waters, N.J., Waterfield, C.J., Farrant, R.D., Holmes, E., Nicholson, J.K., 2005. Metabonomic deconvolution of embedded toxicity: application to thioacetamide hepato-and nephrotoxicity. Chem. Res. Toxicol. 18, 639-654.

Wei, X., Ma, Z., Fontanilla, C., Zhao, L., Xu, Z., Taggliabraci, V., Johnstone, B., Dodel, R., Farlow, M., Du, Y., 2008. Caffeic acid phenethyl ester prevents cerebellar granule neurons (CGNs) against glutamate-induced neurotoxicity. Neuroscience $155,1098-1105$

Zhou, J., Zhou, J., Zhong, X., Chen, L., Yang, X., 1996. Abnormal expressions of hepatocellular proteins and extracellular matrix in CCL $\sim 4$-induced liver injury in rats. Chin. Med. J. Beijing-English Ed. 109, 366-371. 